\title{
Analysis of a Batch Adsorber Analogue for Rapid Screening of Adsorbents for Postcombustion $\mathrm{CO}_{2}$ Capture
}

Vishal Subramanian Balashankar, ${ }^{\dagger}$ Ashwin Kumar Rajagopalan,,$\dagger \odot$ Ruben de Pauw, ${ }^{\dagger}$ Adolfo M. Avila, ${ }^{\S}$ and Arvind Rajendran* ${ }^{*} \dagger$

${ }^{\dagger}$ Department of Chemical and Materials Engineering, University of Alberta, 12th Floor, Donadeo Innovation Centre for Engineering (ICE), 9211-116 Street, Edmonton, Alberta, Canada T6G 1H9

${ }^{\ddagger}$ Department of Chemical Engineering (CHIS-IR), Vrije Universiteit Brussel, Pleinlaan 2, 1050 Brussels, Belgium

${ }^{\S}$ INQUINOA, Universidad Nacional de Tucumán, CONICET, DIPyGI-FACET-UNT, Av. Independencia 1800, C.P. 4000 San

Miguel de Tucumán, Argentina

Supporting Information

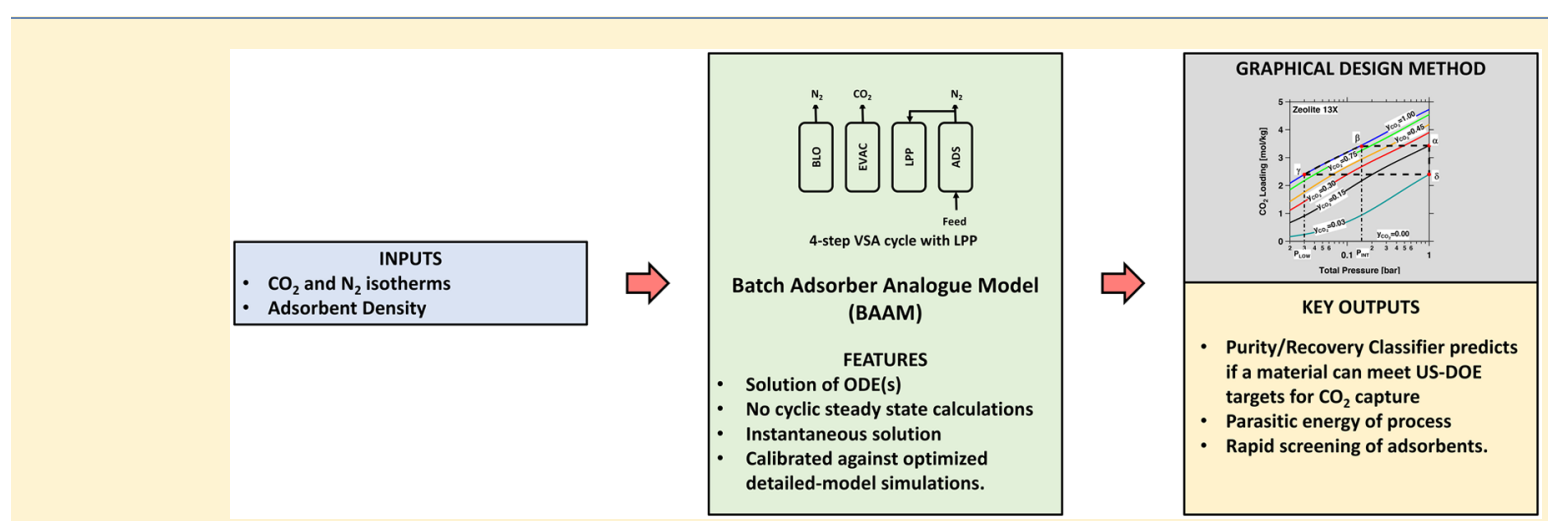

ABSTRACT: A simplified proxy model based on a well-mixed batch adsorber for vacuum swing adsorption (VSA) based $\mathrm{CO}_{2}$ capture from dry postcombustion flue gas is presented. A graphical representation of the model output allows for the rationalization of broad trends of process performance. The results of the simplified model are compared with a detailed VSA model that takes into account mass and heat transfer, column pressure drop, and column switching, in order to understand its potential and limitations. A new classification metric to identify whether an adsorbent can produce $\mathrm{CO}_{2}$ purity and recovery values that meet current U.S. Department of Energy (US-DOE) targets for postcombustion $\mathrm{CO}_{2}$ capture and to calculate the corresponding parasitic energy is developed. The model, which can be evaluated within a few seconds, showed a classification Matthew correlation coefficient of 0.76 compared to 0.39 , the best offered by any traditional metric. The model was also able to predict the energy consumption within $15 \%$ accuracy of the detailed model for $83 \%$ of the adsorbents studied. The developed metric and the correlation are then used to screen the NIST/ARPA-E database to identify promising adsorbents for $\mathrm{CO}_{2}$ capture applications.

\section{INTRODUCTION}

Carbon capture and sequestration (CCS), wherein $\mathrm{CO}_{2}$ emitted from the large point sources is captured, transported, and sequestered underground at high pressures, is a promising technology to combat global warming., Coal-fired power plants constitute a major source of $\mathrm{CO}_{2}$ emissions and hence are an obvious choice for implementing CCS technologies. Postcombustion carbon capture, where $\mathrm{CO}_{2}$ is concentrated from a flue gas that consists of $\sim 15 \% \mathrm{CO}_{2}$ and the rest being $\mathrm{N}_{2}$, $\mathrm{O}_{2}$, and $\mathrm{H}_{2} \mathrm{O}$, carries an advantage that it can be retrofitted to existing coal-fired power plants. Absorption, using aqueous amines such as monoethanolamine (MEA), is the current technology for scrubbing $\mathrm{CO}_{2}$ from the flue gas at large scales. ${ }^{2}$ However, due to some of the limitations posed by this process such as the energy intensive solvent regeneration and the corrosive nature of the solvent, there is a need for the development of alternative technologies for $\mathrm{CO}_{2}$ capture. ${ }^{3}$ In this regard, adsorption based $\mathrm{CO}_{2}$ capture, that uses solid sorbents, has shown potential for reducing the parasitic energy consumption. $^{3-6}$

The choice of an adsorbent is critical to the design of a pressure swing adsorption (PSA), vacuum swing adsorption (VSA), or a temperature swing adsorption (TSA) process. ${ }^{7,8}$ With significant developments being made in organometallic chemistry, the number of adsorbents being developed has seen a dramatic growth in recent years. ${ }^{9-11}$ Hence, it becomes a challenging task when many adsorbents such as metal-organic

Received: November 1, 2018

Revised: January 18, 2019

Accepted: January 18, 2019 
frameworks (MOFs), zeolites, and activated carbons are to be screened for the selection of the best adsorbents for the $\mathrm{CO}_{2}$ capture process. $^{12}$

Several approaches have been suggested for adsorbent screening in the literature. Harlick and Tezel suggested the use of working capacity, which is given by the difference in equilibrium loading between feed and desorption pressures. ${ }^{13}$ Snurr's group, in an experimental study, screened 14 MOFs based on the increasing $\mathrm{CO}_{2}$ adsorption capacity at 0.1 bar pressure. ${ }^{14}$ Krishna et al. ranked a group of zeolites and MOFs based on experimental breakthrough time. ${ }^{15}$ In another study, Krishna proposed the separation potential that combines selectivity and uptake capacity as a metric for screening MOFs. ${ }^{16}$ Lin et al. screened thousands of zeolite and zeolitic imidazolate framework structures based on the parasitic energy load imposed on the power plant using a hybrid pressuretemperature swing adsorption cycle. ${ }^{17}$ Berger et al. developed a simplified method, for a temperature swing adsorption process, to estimate the parasitic energy and used it to screen over 4 million zeolites and zeolitic imidazolite frameworks and found few promising adsorbents with lower energy consumption. ${ }^{18}$

Most of the above-mentioned studies use simple metrics that can be easily calculated based on adsorption isotherm measurements. On the one hand, these metrics are convenient especially when large databases of adsorbents are to be screened. On the other hand, many recent studies that compared the efficacy of these metrics with detailed process simulations have demonstrated their poor reliability. ${ }^{19,20}$ The alternative to these approaches is the use of detailed full-scale process simulations combined with optimization. Here, a detailed model of the $\mathrm{P} / \mathrm{V} /$ TSA system is considered and is optimized to evaluate the best performance that can result from using a certain adsorbent. This detailed approach has been studied by Haghpanah who compared the performance of different carbons and later with zeolite $13 \mathrm{X}^{21}$ Hasan et al. combined material characterization and process optimization to screen the adsorbents based on the cost of capture and compression. ${ }^{22}$ The group of Mazzotti employed this approach for precombustion $\mathrm{CO}_{2}$ capture. ${ }^{23}$ Snurr and co-workers have studied these approaches for screening materials using a two-stage process. ${ }^{24}$ Nikolaidis et al. compared the performance of zeolite 13X and Mg-MOF-74 in an integrated two-stage P/VSA process for postcombustion $\mathrm{CO}_{2}$ capture. $^{25}$ Rajagopalan et al. demonstrated that detailed models are more reliable compared to simple screening metrics. ${ }^{19}$ Khurana and Farooq in a series of papers have explored this approach and concluded that process optimization is essential for a reliable screening. ${ }^{20,26}$ Surrogate models have been discussed in the literature ${ }^{20,27,28}$ to overcome the computational challenges. While these are very powerful, they do not provide physical insight into the performance of a material. Hence, to aid the synthetic chemists, there is a need for simpler models that are easy to solve while providing key insights.

Detailed process-optimization-based screening is perhaps the most reliable approach for adsorbent screening. ${ }^{29}$ However, it is rather computationally demanding and requires the development of sophisticated numerical schemes and the availability of parallel computing power. ${ }^{5}$ There are no straightforward design methods for cyclic adsorption processes, especially when the adsorption isotherm is nonlinear, and when mass and heat transfer effects play an important role. Hence, these processes have to be simulated for 100 s or 1000 s of cycles before this cyclic steady-state performance can be calculated for a given set of operating conditions. Repeating this for 1000s of combinations of operating conditions can be computationally very expensive. Our experience indicates that running multiobjective optimization of simple VSA processes could take up to a few days on multicore desktop workstations. Scaling such approaches for screening material databases that contain hundreds of thousands of adsorbents is indeed a daunting task. Hence, a need exists for models that are complex enough to capture the essential dynamics of the process, while also simple enough for rapid computation.

Maring and Webley proposed a simplified model (referred in this work as MW model) for rapid screening of adsorbents. ${ }^{30}$ In this model, a well-mixed adsorber was considered with no spatial gradients of the intensive process variables. Hence, the model equations of a PSA system, that are coupled algebraic-partial differential equations, were reduced to coupled algebraicordinary differential equations. Further, they also proposed an approach to arrive at a cyclic steady state without having to simulate the cycle multiple times. These two simplifications meant that the MW model can be solved rapidly (on the order of a few seconds) compared to several minutes that is required for the solution of detailed PSA models. The MW model was further used to select adsorbents and to identify the key features of ideal adsorbents. A similar approach has been discussed by Zhao et al. ${ }^{31}$ It is important to note that the key mechanism of separation in adsorption is to change operating conditions in order to "position" the concentration fronts in the column to favor high purity and recovery. In the MW model there is no mechanism to achieve this as spatial gradients are completely eliminated. Hence the MW model will give results identical to a detailed model only under specific conditions. Although the model has been used in the literature, there has been no study that validates the MW model with the detailed process models.

The objective of the current work is to extend the MW model to a different cycle configuration and to develop a graphical design method. The model is compared with a detailed VSA model in order to understand its advantages and limitations. Then, the model is used to compare the performances of four adsorbents and illustrate the graphical approach of the process design. A classification model to identify whether a certain adsorbent can provide $\mathrm{Pu}_{\mathrm{CO}_{2}} \geq 95 \%$ and $\mathrm{Re}_{\mathrm{CO}_{2}} \geq 90 \%$, a target that is set by the U.S. Department of Energy for $\mathrm{CO}_{2}$ capture, is developed. Further, a simple approach to estimate the parasitic energy consumption is developed and validated. Finally, this approach is used to screen adsorbents from the NIST/ARPA-E adsorbent database to identify the potential materials for postcombustion $\mathrm{CO}_{2}$ capture.

At the outset, it is important to stress that the goal of the model, both MW and the current one, is not to represent the dynamics of the actual VSA process. In fact, as shown by Maring and Webley and in this work, the assumptions made will not allow a suitable description. Instead, the target is to develop a "reliable proxy" that can be calibrated using detailed models in order to enable rapid evaluation of a large number of adsorbents.

\section{BATCH ADSORBER ANALOGUE MODEL (BAAM)}

The model that is considered in this work is based on the framework developed by Maring and Webley $^{30}$ with a few modifications. In order to differentiate the two approaches, we will refer to the current model as the batch adsorber analogue model (BAAM). 


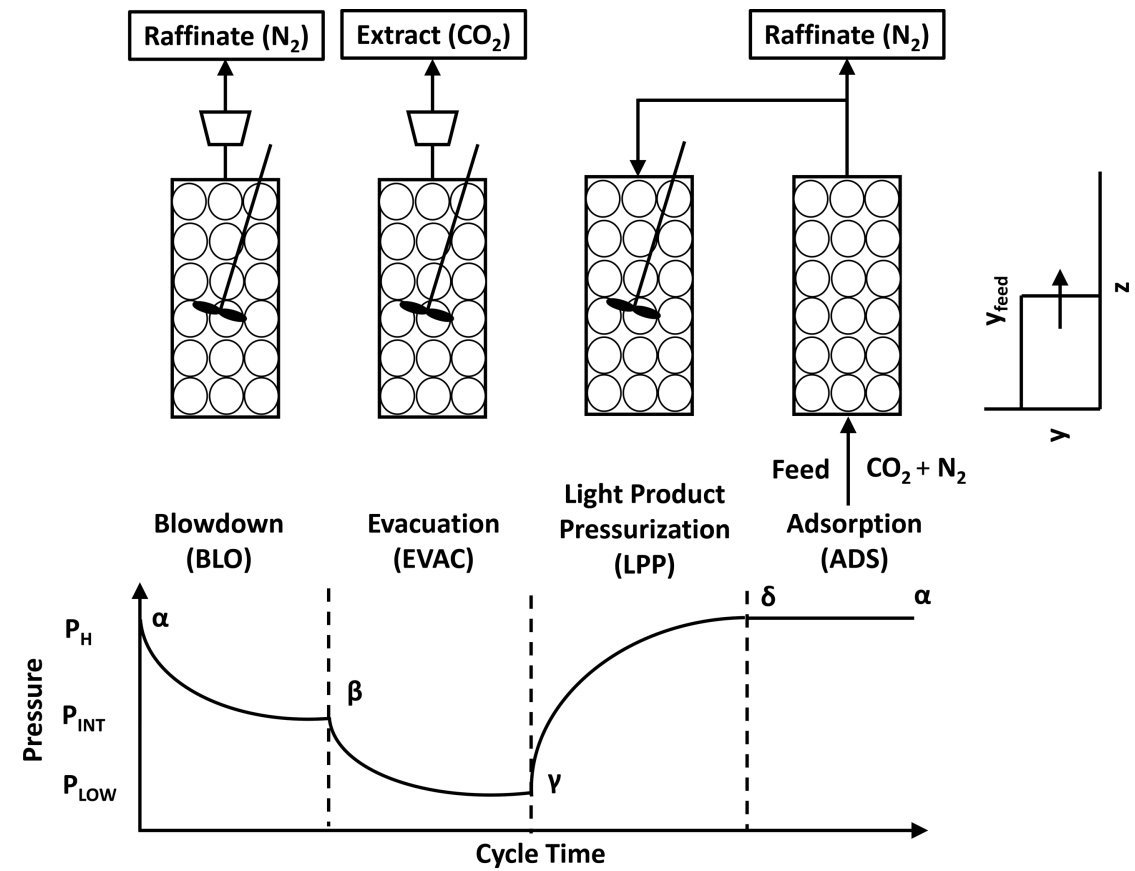

Figure 1. Schematic of a four-step VSA cycle with light product pressurization (LPP).

2.1. Assumptions. A batch adsorber filled with solid adsorbents is considered for developing the model equations. The mass of the adsorbent is taken to be $1 \mathrm{~kg}$, and the volume of the column needed to accommodate the adsorbent is computed based on the bed porosity and adsorbent density. The bed voidage $(\epsilon)$ is considered to be 0.37 . The simplified mathematical model is based on the following assumptions:

- The column is well-mixed and homogeneous, meaning that concentration, pressure, and temperature gradients, both axial and radial, are absent across the column.

- The fluid phase behaves ideally.

- Heat effects are not considered and the column is isothermal.

- There is no mass transfer resistance; i.e., the equilibrium between the gas and solid phase is instantaneous.

- The adsorbent properties and bed voidage are uniform throughout the column.

The key difference between the BAAM and MW model is the assumption of isothermality. Although heat effects are important, for a particular cycle configuration that is considered here (description given in the following section), the heat effects seem to play a lesser role in deciding the cyclic steady state performance. $^{20}$ Evidence for this comes from experimental measurements from a pilot plant containing $\sim 80 \mathrm{~kg}$ of adsorbent. $^{32}$ It was observed that during the initial periods, the bed temperatures increased by $\sim 60{ }^{\circ} \mathrm{C}$ above the feed temperature, and then dropped to $<10{ }^{\circ} \mathrm{C}$ above the feed temperature, once the system reached the cyclic steady state. The second observation arises from detailed optimization studies that revealed that models with the assumption of isothermality yielded results comparable to those that accounted for heat effects. ${ }^{20}$ As will be shown later, the assumption of isothermal conditions also allows for a simplified graphical representation that could aid in the easy understanding of the process. The assumption related to mass transfer resistance also deviates from reality. Real systems do have finite mass transfer rates. Although many of the systems that have been studied for postcombustion $\mathrm{CO}_{2}$ capture separate $\mathrm{CO}_{2}$ and $\mathrm{N}_{2}$ on the basis of their equilibrium properties, mass transfer rates have a major impact on achievable purity/recovery and the process productivity.

2.2. Cycle Configuration and Mathematical Model. Haghpanah et al. evaluated complex VSA cycles for the postcombustion $\mathrm{CO}_{2}$ capture with zeolite $13 \mathrm{X}$ as the adsorbent, and the four-step VSA cycle with light product pressurization (LPP) was shown to be the best-performing cycle in terms of least energy consumption while guaranteeing high $\mathrm{CO}_{2}$ purity and recovery. ${ }^{33}$ Further, this cycle was also demonstrated experimentally at a pilot-scale to produce $94.8 \pm 1 \% \mathrm{CO}_{2}$ purity and $89.7 \pm 5.6 \% \mathrm{CO}_{2}$ recovery, thereby achieving the US-DOE target in a single stage. ${ }^{32}$ The BAAM is developed for a four-step VSA cycle with LPP, which comprises adsorption, blowdown, evacuation, and light product pressurization steps. The schematic of this cycle is shown in Figure 1.

The total number of moles of a species " $i$ " in the column, $N_{i, \text { total }}$, is given by the sum of the number of moles of species " $i$ " in the fluid phase, $N_{i, \text { fluid }}$ and in the solid phase, $N_{i, \text { solid }}$.

$$
N_{i, \text { total }}=N_{i, \text { fluid }}+N_{i, \text { solid }}
$$

where,

$$
\begin{aligned}
& N_{i, \text { fluid }}=\frac{P y_{i} V \epsilon}{R_{\mathrm{g}} T} \\
& N_{i, \text { solid }}=w q_{i}^{*}
\end{aligned}
$$

In eqs $1-3, P, T$, and $y_{i}$ are the fluid phase total pressure, temperature, and fluid phase composition of species " $i$ " respectively, $V$ and $\epsilon$ refer to the column volume and its voidage, $R_{\mathrm{g}}$ denotes the universal gas constant, $w$ is the mass of the adsorbent, and $q_{i}^{*}$ is the equilibrium solid phase loading of species " $i$ " which is given by a suitable isotherm expression as below:

$$
q_{i}^{*}=f\left(P, T, y_{i}\right)
$$


Since isothermal conditions are considered, once the operating temperature is fixed, only two intensive variables $P$ and $y_{i}$ need to be specified in order to calculate the $N_{i, \text { fluid }}$ and $N_{i, \text { solid. }}$ In the system studied, the feed consists of two components, $\mathrm{CO}_{2}$, the strongly adsorbing component, and $\mathrm{N}_{2}$, the weakly adsorbing component. A brief description of each step of the PSA cycle is given below.

Blowdown (BLO) $(\alpha \rightarrow \beta)$. The batch adsorber is initially saturated with the feed composition $\left(y_{\mathrm{CO}_{2}}^{\text {feed }}\right)$ at high pressure $P_{\mathrm{H}}$. This is referred to as state $\alpha$, also illustrated in Figure 1. In blowdown step, a vacuum is applied to the column thereby reducing the pressure from $P_{\mathrm{H}}$ to an intermediate pressure, $P_{\text {INT }}$. The aim of this step is to remove the weakly adsorbing component $\left(\mathrm{N}_{2}\right)$ from the column, leaving the bed concentrated with strongly adsorbing component $\left(\mathrm{CO}_{2}\right)$. This step can be modeled by writing the mass balances around the batch adsorber that results in the following two ordinary differential equations (ODE).

Overall mass balance:

$$
\frac{V \epsilon}{R_{\mathrm{g}} T} \frac{\mathrm{d} P}{\mathrm{~d} t}+w\left(\frac{\mathrm{d} q_{\mathrm{CO}_{2}}^{*}}{\mathrm{~d} t}+\frac{\mathrm{d} q_{\mathrm{N}_{2}}^{*}}{\mathrm{~d} t}\right)=-\mathrm{Q}
$$

Component mass balance:

$$
\frac{V \epsilon}{R_{\mathrm{g}} T} \frac{\mathrm{d} P y_{\mathrm{CO}_{2}}}{\mathrm{~d} t}+w \frac{\mathrm{d} q_{\mathrm{CO}_{2}}^{*}}{\mathrm{~d} t}=-Q y_{\mathrm{CO}_{2}}
$$

where $Q$ refers to the total molar flow rate leaving the column. The above equations can be combined to eliminate $Q$ and $t$ resulting in

$$
\frac{\mathrm{d} y_{\mathrm{CO}_{2}}}{\mathrm{~d} P}=\frac{a_{1} y_{\mathrm{CO}_{2}}-a_{2}}{f_{2}-f_{1} y_{\mathrm{CO}_{2}}}
$$

where

$$
\begin{aligned}
& a_{1}=\frac{V \epsilon}{R_{\mathrm{g}} T}+w\left(\frac{\partial q_{\mathrm{CO}_{2}}^{*}}{\partial P}+\frac{\partial q_{\mathrm{N}_{2}}^{*}}{\partial P}\right) \\
& a_{2}=\frac{y_{\mathrm{CO}_{2}} V \epsilon}{R_{\mathrm{g}} T}+w \frac{\partial q_{\mathrm{CO}_{2}}^{*}}{\partial P} \\
& f_{1}=w\left(\frac{\partial q_{\mathrm{CO}_{2}}^{*}}{\partial y_{\mathrm{CO}_{2}}}+\frac{\partial q_{\mathrm{N}_{2}}^{*}}{\partial y_{\mathrm{CO}_{2}}}\right) \\
& f_{2}=\frac{P V \epsilon}{\mathrm{R}_{\mathrm{g}} T}+w \frac{\partial q_{\mathrm{CO}_{2}}^{*}}{\partial y_{\mathrm{CO}_{2}}}
\end{aligned}
$$

The solution of eq 7 gives the gas phase composition, $y_{\mathrm{CO}_{2}}$, as a function of total pressure, $P$. The blowdown step is carried out until $P_{\text {INT }}$ is reached. The state of the adsorber at the intermediate pressure is labeled as $\beta$. On the basis of states $\alpha$ and $\beta$, the number of moles of $\mathrm{CO}_{2}$ and $\mathrm{N}_{2}$ removed from the adsorber can be easily calculated with simple mass balance equations. The adiabatic work done by the vacuum pump, that delivers the gas at 1 bar pressure, assuming a constant isentropic efficiency of $\eta=72 \%$ is given by

$$
W_{\mathrm{BLO}}=\int_{N_{\text {total }}^{\alpha}}^{N_{\text {total }}^{\beta}} \frac{1}{\eta} \frac{k}{k-1} R_{\mathrm{g}} T\left[\left(\frac{1}{P}\right)^{(k-1) / k}-1\right] \mathrm{d} N
$$

where $k$ is the adiabatic constant. Note that the value of $\eta=72 \%$ used in this study is consistent with many theoretical calculations presented in the literature. A few experimental studies that have measured vacuum pump efficiencies at very low pressures report lower values of $\sim 30 \%$. $^{32}$

Evacuation (EVAC) $(\beta \rightarrow \gamma)$. The evacuation step starts from state $\beta$ and the adsorber is evacuated until the low pressure, $P_{\text {LOW }}$, is reached. The extract product $\left(\mathrm{CO}_{2}\right)$ is collected in this step. The state at the end of evacuation step is denoted by $\gamma$. The same set of mass balance equations and the work done by the vacuum pump, as described for the blowdown step is applicable for the evacuation step for a value of pressure ranging from $P_{\text {INT }}$ to $P_{\text {LOW. }}$ The energy consumption for this step is provided by

$$
W_{\text {EVAC }}=\int_{N_{\text {total }}^{\beta}}^{N_{\text {total }}^{\gamma}} \frac{1}{\eta} \frac{k}{k-1} R_{\mathrm{g}} T\left[\left(\frac{1}{P}\right)^{(k-1) / k}-1\right] \mathrm{d} N
$$

Light Product Pressurization (LPP) $(\gamma \rightarrow \delta)$. The adsorber which is at low pressure, $P_{\mathrm{LOW}}$, at the end of evacuation, needs to be raised to high pressure, $P_{\mathrm{H}}$. This is achieved by pressurizing the adsorber with the raffinate product from the adsorption step. Note that the adsorption step, as will be described below, will start with the state $\delta$, which is the end of LPP step. Hence, in the LPP step, the adsorber is pressurized using a stream whose composition is $y_{\mathrm{CO}_{2}}^{\delta}$. This step is assumed to not consume any power. The number of moles $\left(N_{\mathrm{LPP}}\right)$ needed to pressurize the column from $P_{\mathrm{LOW}}$ to $P_{\mathrm{H}}$ is calculated by solving the mass balance equations as given in eqs $11-12$ where $y_{\mathrm{CO}_{2}}^{\delta}$ is the $\mathrm{CO}_{2}$ composition in the column at the end of LPP step.

Overall mass balance:

$$
\left(N_{\mathrm{CO}_{2}, \text { total }}^{\gamma}+N_{\mathrm{N}_{2}, \text { total }}^{\gamma}\right)+N_{\mathrm{LPP}}=\left(N_{\mathrm{CO}_{2}, \text { total }}^{\delta}+N_{\mathrm{N}_{2}, \text { total }}^{\delta}\right)
$$

Component mass balance:

$$
N_{\mathrm{CO}_{2}, \text { total }}^{\gamma}+N_{\mathrm{LPP}} y_{\mathrm{CO}_{2}}^{\delta}=N_{\mathrm{CO}_{2}, \text { total }}^{\delta}
$$

In the above equations, $N_{\mathrm{LPP}}$ and $y_{\mathrm{CO}_{2}}^{\delta}$ are the unknowns which are solved based on the known initial state, $\gamma$ (end of evacuation step). Note that this step is different from the MW model that considered pressurization with the feed.

Adsorption (ADS) $(\delta \rightarrow \alpha)$. The column at the state $\delta$ represents the initial condition for the adsorption step. The feed is supplied to the column at constant high pressure $P_{\mathrm{H}}$ and temperature $T^{\text {feed }}$. This step is modeled differently compared to the other steps. Here, the adsorber is modeled as a standard adsorption column that is originally saturated with the gas as given by state $\delta$. The feed gas is considered to flow through the column like a plug that breaks through once the column is completely saturated with the feed. The aim here, as it was with the MW model, is to keep the mathematics of the model simple. Under these assumptions, the two mass balances are given by

Overall mass balance:

$$
\begin{aligned}
& \left(N_{\mathrm{CO}_{2}, \text { total }}^{\delta}+N_{\mathrm{N}_{2}, \text { total }}^{\delta}\right)+N_{\text {feed }}=\left(N_{\mathrm{CO}_{2}, \text { total }}^{\alpha}+N_{\mathrm{N}_{2}, \text { total }}^{\alpha}\right) \\
& \quad+N_{\text {raff }}
\end{aligned}
$$




$$
N_{\mathrm{CO}_{2}, \text { total }}^{\delta}+N_{\text {feed }} y_{\mathrm{CO}_{2}}^{\text {feed }}=N_{\mathrm{CO}_{2} \text {,total }}^{\alpha}+N_{\text {raff }} y_{\mathrm{CO}_{2}}^{\delta}
$$

$N_{\text {feed }}$ and $N_{\text {raff }}$ are calculated by solving the nonlinear equations given in eq 13 and 14. At the end of adsorption step, the column reaches state $\alpha$. Note that the energy consumption during the feed step is not calculated as its contribution is negligible. ${ }^{3,19}$

It is worth noting here that the sequence of steps starts and returns to state $\alpha$ (beginning of the blowdown step and end of the adsorption step), passing through states $\beta, \gamma$, and $\delta$. This avoids the need to repeat the calculations for multiple cycles, thereby significantly reducing the computational time. Further, once the adsorbent properties, feed pressure, composition, and temperature are fixed, the model has only two design variables, namely, $P_{\text {INT }}$ and $P_{\text {LOW. }}$. Considering the simplicity of the model, the design space can be quickly scanned.

Performance Indicators. $\mathrm{CO}_{2}$ purity, recovery, energy consumption, and working capacity are the performance indicators for the VSA process. Purity is the ratio of the number of moles of $\mathrm{CO}_{2}$ obtained to the total number of moles obtained in the evacuation step.

$$
\begin{aligned}
& \text { Purity, } P u_{\mathrm{CO}_{2}}[\%] \\
& \quad=\left(\frac{N_{\mathrm{CO}_{2}, \text { total }}^{\beta}-N_{\mathrm{CO}_{2}, \text { total }}^{\gamma}}{N_{\mathrm{CO}_{2}, \text { total }}^{\beta}-N_{\mathrm{CO}_{2}, \text { total }}^{\gamma}+N_{\mathrm{N}_{2} \text {,total }}^{\beta}-N_{\mathrm{N}_{2} \text {,total }}^{\gamma}}\right) \times 100
\end{aligned}
$$

Recovery is defined as the ratio of total moles of $\mathrm{CO}_{2}$ collected in the evacuation step to the number of moles of $\mathrm{CO}_{2}$ in the feed.

$$
\text { Recovery, } \operatorname{Re}_{\mathrm{CO}_{2}}[\%]=\left(\frac{N_{\mathrm{CO}_{2} \text {,total }}^{\beta}-N_{\mathrm{CO}_{2} \text {,total }}^{\gamma}}{N_{\text {feed }} y_{\mathrm{CO}_{2}}^{\text {feed }}}\right) \times 100
$$

The total-energy consumption is the sum of work done by the vacuum pump in the blowdown and evacuation step.

$$
\begin{aligned}
& \text { Energy, } E n\left[\frac{\mathrm{kWh}_{\mathrm{e}}}{\text { tonne } \mathrm{CO}_{2} \mathrm{cap}}\right] \\
& =\frac{W_{\mathrm{BLO}}+W_{\mathrm{EVAC}}}{\left(N_{\mathrm{CO}_{2}, \text { total }}^{\beta}-N_{\mathrm{CO}_{2}, \text { total }}^{\gamma}\right) \mathrm{M}_{\mathrm{CO}_{2}}}
\end{aligned}
$$

where $\mathrm{M}_{\mathrm{CO}_{2}}$ is the molecular weight of $\mathrm{CO}_{2}$. Note that the energy calculated here is in electrical units, and hence, the units carry a subscript "e". Since the model assumes instantaneous equilibrium, i.e., a $100 \%$ efficient column, the productivity cannot be calculated. In order to obtain an estimate of the amount of adsorbent required, the working capacity can be considered. This quantity is defined as the number of moles of $\mathrm{CO}_{2}$ from the evacuation step per $\mathrm{m}^{3}$ of the adsorbent.

$$
\begin{aligned}
& \text { Working capacity, } W C_{\mathrm{CO}_{2}}\left[\frac{\mathrm{mol} \mathrm{CO}}{\mathrm{m}^{3} \text { of adsorbent }}\right] \\
& =\frac{N_{\mathrm{CO}_{2} \text {,total }}^{\beta}-N_{\mathrm{CO}_{2} \text {,total }}^{\gamma}}{V(1-\epsilon)}
\end{aligned}
$$

In this work, the ODE, given by eq 7 , is solved in MATLAB R2017a using ode23s solver with an initial condition of $y_{i}=y_{\mathrm{CO}_{2}}^{\mathrm{feed}}$ at $P=P_{\mathrm{H}}$. The coupled nonlinear mass balance equations in the LPP and ADS steps, given by eqs $11-14$, are solved using fsolve solver with trust-region-dogleg algorithm. All the simulations reported in this work are computed using the desktop computer with INTEL Core $2.80 \mathrm{GHz}$ processor and $8.00 \mathrm{~GB}$ of RAM.

2.3. Detailed Model and Process Optimization. The detailed model, that is used to predict the adsorption column dynamics for a given PSA cycle configuration, solves coupled partial differential equations of mass, momentum, and heat balances with cyclic boundary conditions. ${ }^{5}$ The detailed mathematical equations and corresponding boundary conditions are given in the Supporting Information. It is a nonisothermal and non-isobaric model which is robust and rigorous. The set of partial differential equations are discretized spatially using a finite volume technique, and the resulting ODEs are solved using an inbuilt MATLAB ODE solver. The detailed model has been validated against lab-scale ${ }^{34}$ and pilot-scale ${ }^{32}$ experimental results.

For the optimization of the VSA process, a genetic algorithm (GA) that works in conjunction with the detailed model is used. The GA chooses the set of decision variables, typically the duration of the various steps, velocity of the feed, and pressure levels $P_{\text {INT }}$ and $P_{\text {LOW }}$, and passes them to the VSA simulator. The dynamics of the process under these conditions is evaluated, and the performance at cyclic steady-state conditions is evaluated and returned to the GA. The GA proceeds from one generation to the next by improving the objective functions until no further improvement is possible. Multiobjective optimization problems result in Pareto curves that provide the best trade-off between the various objective functions. Details of this approach have been discussed elsewhere. ${ }^{5}$

\section{ILLUSTRATION AND VALIDATION OF THE BAAM}

In this section, the developed BAAM is illustrated using four adsorbents that have been studied in a previous work. ${ }^{19}$ The high pressure, $P_{\mathrm{H}}$, is fixed at $1 \mathrm{bar}$ for all the simulations since it has been shown that increasing the adsorption pressure more than 1 bar has a significant effect on the overall energy consumption as the feed, which consists majorly of $\mathrm{N}_{2}$, has to be compressed to higher pressure. ${ }^{5,30}$ The lower bound of $P_{\text {LOW }}$ in this study is set to 0.03 bar, a pressure that was achieved in pilot plant experiments. ${ }^{32}$ Due to the isothermal operation of the column, the temperature is taken to be the feed temperature of $298.15 \mathrm{~K}$. Thus, the BAAM cycling between atmospheric pressure and low vacuum pressures at a fixed feed temperature of $298.15 \mathrm{~K}$ is considered for all the simulations. The feed gas stream is considered to consist of $15 \mathrm{~mol} \%$ of $\mathrm{CO}_{2}$ and $85 \mathrm{~mol} \%$ $\mathrm{N}_{2}$ at 1 bar and $298.15 \mathrm{~K}$. In this work, the flue gas is considered to be pre-dried. It is important to highlight that drying of the flue gas is indeed energy intensive, and any comparisons to other processes should be made with caution. ${ }^{35}$

3.1. Process Description. The four adsorbents considered in this study for illustrating the features of the model are two MOFs, namely, Mg-MOF-74 and UTSA-16, zeolite 13X, and a variety of coconut-shell activated carbon (CS-AC). The properties of these adsorbents have been given in the previous publication. ${ }^{19}$ The isotherms of $\mathrm{CO}_{2}$ and $\mathrm{N}_{2}$ are described using a dual-site Langmuir (DSL) isotherm model:

$$
\begin{aligned}
& q_{i}^{*}=\frac{q_{\mathrm{sb}, i} b_{i} C_{i}}{1+b_{i} C_{i}}+\frac{q_{\mathrm{sd}, i} d_{i} C_{i}}{1+d_{i} C_{i}} \\
& b_{i}=b_{0, i} e^{-\Delta U_{b, i} / R_{\mathrm{g}} T} \\
& d_{i}=d_{0, i} e^{-\Delta U_{d, i} / R_{\mathrm{g}} T}
\end{aligned}
$$



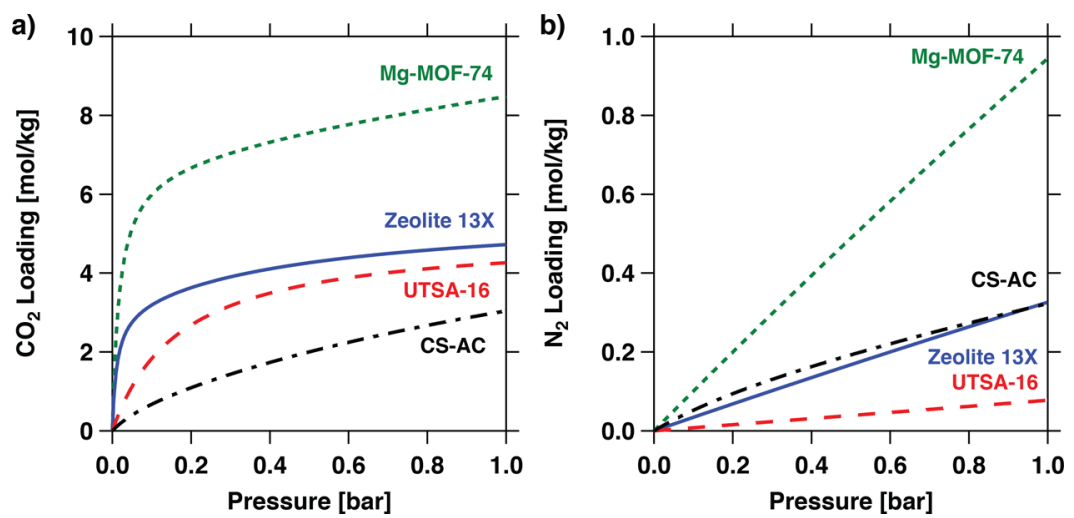

Figure 2. Pure-component isotherms of (a) $\mathrm{CO}_{2}$ and (b) $\mathrm{N}_{2}$ at $298.15 \mathrm{~K}$ for the four adsorbents studied [reproduced from Rajagopalan et al. ${ }^{19}$ Copyright 2016 Elsevier].

Table 1. Dual-Site Langmuir Pure-Component Isotherm Parameters of $\mathrm{CO}_{2}$ and $\mathrm{N}_{2}$ on the Adsorbents Considered ${ }^{19}$

\begin{tabular}{|c|c|c|c|c|c|c|c|c|}
\hline adsorbent & particle density $\left[\mathrm{kg} / \mathrm{m}^{3}\right]$ & adsorbate & $q_{\mathrm{sb}, \mathrm{i}}[\mathrm{mol} / \mathrm{kg}]$ & $q_{\mathrm{sd}, \mathrm{i}}[\mathrm{mol} / \mathrm{kg}]$ & $b_{0, \mathrm{i}}\left[\mathrm{m}^{3} / \mathrm{mol}\right]$ & $d_{0, \mathrm{i}}\left[\mathrm{m}^{3} / \mathrm{mol}\right]$ & $-\Delta U_{\mathrm{b}, \mathrm{i}}[\mathrm{kJ} / \mathrm{mol}]$ & $-\Delta U_{\mathrm{d}, \mathrm{i}}[\mathrm{kJ} / \mathrm{mol}]$ \\
\hline \multirow[t]{2}{*}{ Mg-MOF-74 } & \multirow[t]{2}{*}{588.25} & $\mathrm{CO}_{2}$ & 6.80 & \multirow[t]{2}{*}{9.90} & $1.81 \times 10^{-7}$ & \multirow[t]{2}{*}{$1.06 \times 10^{-6}$} & 39.30 & \multirow[t]{2}{*}{21.20} \\
\hline & & $\mathrm{N}_{2}$ & 14.00 & & $3.45 \times 10^{-6}$ & & 15.50 & \\
\hline \multirow[t]{2}{*}{ zeolite $13 \mathrm{X}$} & \multirow[t]{2}{*}{1130.00} & $\mathrm{CO}_{2}$ & 3.09 & \multirow[t]{2}{*}{2.54} & $8.65 \times 10^{-7}$ & \multirow[t]{2}{*}{$2.63 \times 10^{-8}$} & 36.60 & \multirow[t]{2}{*}{35.70} \\
\hline & & $\mathrm{N}_{2}$ & 5.84 & & $2.50 \times 10^{-6}$ & & 15.80 & \\
\hline \multirow[t]{2}{*}{ UTSA-16 } & \multirow[t]{2}{*}{1092.00} & $\mathrm{CO}_{2}$ & 5.00 & \multirow[t]{2}{*}{3.00} & $6.24 \times 10^{-7}$ & \multirow[t]{2}{*}{$1.87 \times 10^{-23}$} & 30.60 & \multirow[t]{2}{*}{44.70} \\
\hline & & $\mathrm{N}_{2}$ & 12.70 & & $2.96 \times 10^{-6}$ & & 9.77 & \\
\hline \multirow[t]{2}{*}{ CS-AC } & \multirow[t]{2}{*}{799.50} & $\mathrm{CO}_{2}$ & 0.59 & 7.51 & $9.40 \times 10^{-6}$ & $1.04 \times 10^{-5}$ & 25.61 & 17.55 \\
\hline & & $\mathrm{N}_{2}$ & 0.16 & 41.30 & $1.81 \times 10^{-3}$ & $1.72 \times 10^{-12}$ & 8.67 & 44.90 \\
\hline
\end{tabular}

where $q_{i}^{*}$ is the equilibrium solid phase loading corresponding to a fluid phase concentration of $C_{i}$. The constants $q_{\mathrm{sb}, i}, q_{\mathrm{sd}, i}, b_{i}$, and $d_{i}$ are the equilibrium saturation solid phase loadings and affinity parameters corresponding to the sites " $b$ " and " $d$ ", respectively. The constants $b_{0, i}$ and $d_{0, i}$ are the pre-exponential factors, and $\Delta U_{b, i}$ and $\Delta U_{d, i}$ are the internal energies. Note that " $b$ " and " $d$ " refer to the high and low energy sites, respectively. The single component isotherms of $\mathrm{CO}_{2}$ and $\mathrm{N}_{2}$ on $\mathrm{Mg}-\mathrm{MOF}-74$, zeolite 13X, UTSA-16 and CS-AC are depicted in Figure 2, and the dual-site Langmuir isotherm parameters that are used to fit the adsorption equilibrium measurements of the same are given in Table 1. Note Mg-MOF-74 has the highest $\mathrm{CO}_{2}$ and $\mathrm{N}_{2}$ capacity and affinities compared to the other three materials. Zeolite 13X has the next strongest $\mathrm{CO}_{2}$ affinity. UTSA-16 has a moderate $\mathrm{CO}_{2}$ affinity but the lowest $\mathrm{N}_{2}$ affinity. Finally, CS-AC has a low $\mathrm{CO}_{2}$ affinity but a high $\mathrm{N}_{2}$ affinity. The extended DSL isotherm model is assumed to describe the competitive nature adequately:

$$
\begin{aligned}
& q_{\mathrm{CO}_{2}}^{*}= \frac{q_{\mathrm{sb}, \mathrm{CO}_{2}} b_{\mathrm{CO}_{2}} C_{\mathrm{CO}_{2}}}{1+b_{\mathrm{CO}_{2}} C_{\mathrm{CO}_{2}}+b_{\mathrm{N}_{2}} C_{\mathrm{N}_{2}}} \\
&+\frac{q_{\mathrm{sd}, \mathrm{CO}_{2}} d_{\mathrm{CO}_{2}} C_{\mathrm{CO}_{2}}}{1+d_{\mathrm{CO}_{2}} C_{\mathrm{CO}_{2}}+d_{\mathrm{N}_{2}} C_{\mathrm{N}_{2}}} \\
& q_{\mathrm{N}_{2}}^{*}= \frac{q_{{\mathrm{sb}, \mathrm{N}_{2}} b_{\mathrm{N}_{2}} C_{\mathrm{N}_{2}}}^{1+b_{\mathrm{CO}_{2}} C_{\mathrm{CO}_{2}}+b_{\mathrm{N}_{2}} C_{\mathrm{N}_{2}}}}{+} \\
&+\frac{q_{\mathrm{sd}, \mathrm{N}_{2}} d_{\mathrm{N}_{2}} C_{\mathrm{N}_{2}}}{1+d_{\mathrm{CO}_{2}} C_{\mathrm{CO}_{2}}+d_{\mathrm{N}_{2}} C_{\mathrm{N}_{2}}}
\end{aligned}
$$

The BAAM is run for fixed values of $P_{\mathrm{H}}=1 \mathrm{bar}, P_{\mathrm{INT}}=0.15$ bar, $P_{\text {LOW }}=0.03$ bar, and $T^{\text {feed }}=298.15 \mathrm{~K}$ for the four adsorbents. The calculated results of each step of the cycle are plotted in the respective $\mathrm{CO}_{2}-\mathrm{N}_{2}$ competitive isotherm of the two adsorbents in Figure 3. The competitive loadings, for different values of $y_{\mathrm{CO}_{2}}$ calculated from eqs 20 and 21 , are plotted as a function of the total pressure. A semilog plot is used in order to illustrate the behavior at low pressures. In Figure 3, the black dashed line provides solution of the BAAM that are represented as transitions between the different states for zeolite 13X (Figure 3a,b) and CS-AC (Figures 3c,d). Similar plots for Mg-MOF-74 and UTSA-16 are provided in the Supporting Information. The case of zeolite $13 \mathrm{X}$ is discussed first. At state $\alpha$, the bed is completely saturated with the feed $\mathrm{CO}_{2}$ concentration, $y_{\mathrm{CO}_{2}}=$ 0.15 . During the blowdown step, $y_{\mathrm{CO}_{2}}$ in the column increases as the weakly adsorbing component $\mathrm{N}_{2}$ is removed from the column and is depicted by moving along the black dashed line in Figure $3 \mathrm{a}, \mathrm{b}$ from $\alpha$ to $\beta$. The $\mathrm{CO}_{2}$ solid phase loading remains almost constant until $\mathrm{CO}_{2}$ composition in the adsorber becomes $y_{\mathrm{CO}_{2}} \approx 1.00$. Thereafter, in the evacuation step, the $\mathrm{CO}_{2}$ loading decreases along the pure $\mathrm{CO}_{2}$ isotherm until the state $\gamma$, corresponding to $P_{\mathrm{LOW}}=0.03$ bar is reached. The LPP step, represented by the transition from $\gamma$ to $\delta$, is nearly a straight line on the $\mathrm{CO}_{2}$ isotherm plot that can be identified by the intersection of a horizontal line from state $\gamma$, and a vertical line from $P_{\mathrm{H}}=1$ bar. The adsorption step moves along the vertical line, $P_{H}=1$ bar until state $\alpha$ is reached. Similar trends are observed for UTSA-16 and Mg-MOF-74.

In the case of CS-AC (Figure 3c,d), there is a significant decrease in the $\mathrm{CO}_{2}$ loading as one moves from $\alpha$ to $\beta$. Further, at $P_{\mathrm{INT}}=0.15$ bar, the $\mathrm{CO}_{2}$ composition is $y_{\mathrm{CO}_{2}}=0.65$ compared to $y_{\mathrm{CO}_{2}} \approx 1.00$ in the case of zeolite $13 \mathrm{X}$. The inferior performance of CS-AC can be explained by observing the transition in $\mathrm{N}_{2}$ isotherm in Figure $3 \mathrm{~d}$ that indicates that a significant amount of $\mathrm{N}_{2}$ is left in the column at $P_{\text {INT }}=0.15$ bar. This observation can be explained by a lower selectivity and a weak $\mathrm{CO}_{2}$ competition, thereby affecting the $\mathrm{CO}_{2}$ purity and 


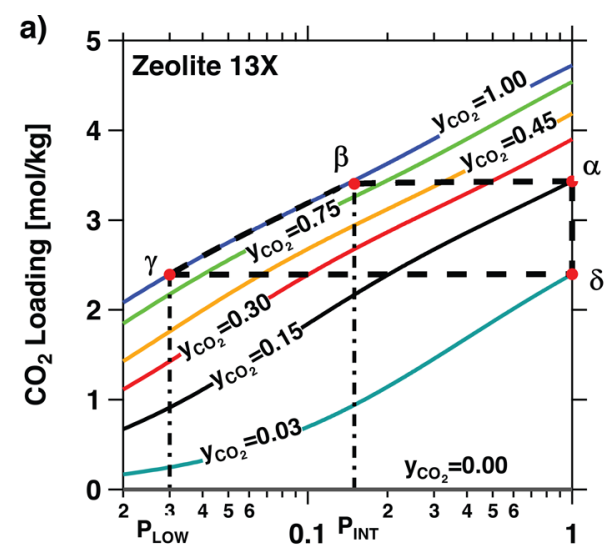

Total Pressure [bar]

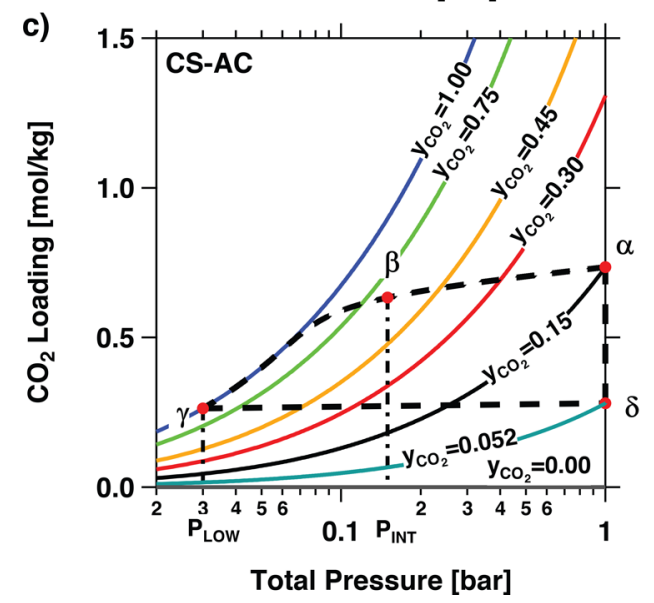

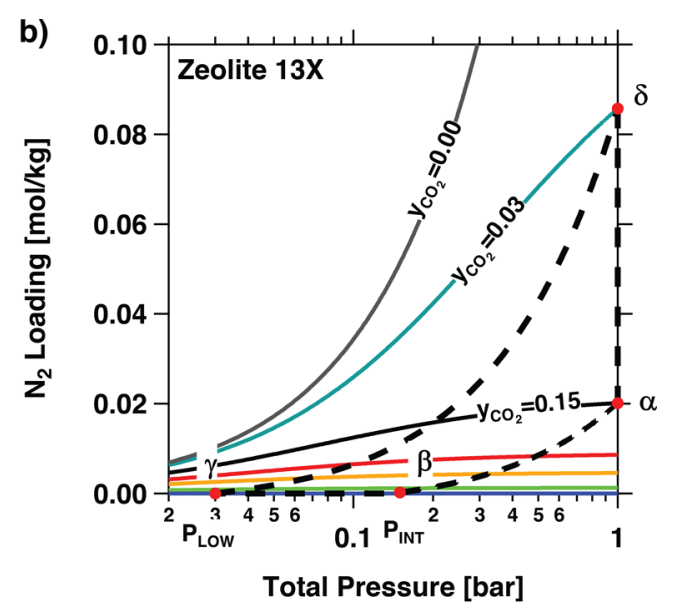

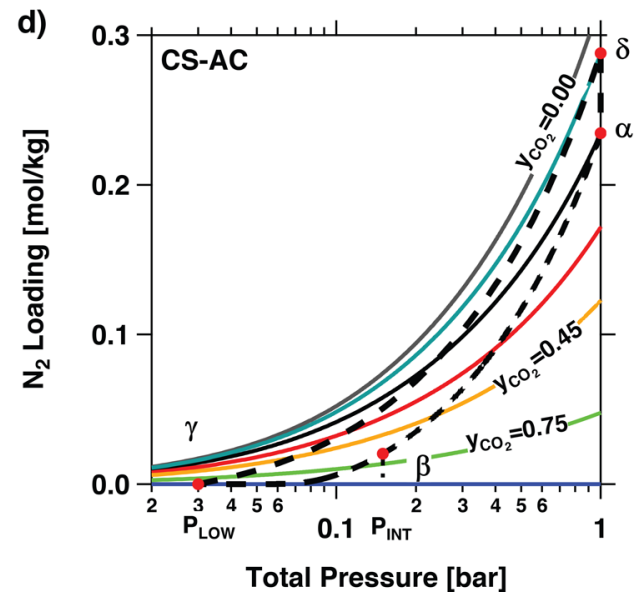

Figure 3. Transitions (black dashed lines) of the four step VSA cycle with LPP calculated using the BAAM. (a) $\mathrm{CO}_{2}$ isotherm for zeolite $13 \mathrm{X}$; (b) $\mathrm{N}_{2}$ isotherm for zeolite $13 \mathrm{X}$; (c) $\mathrm{CO}_{2}$ isotherm for CS-AC; and (d) $\mathrm{N}_{2}$ isotherm for CS-AC. The solid lines indicate the competitive $\mathrm{CO}_{2} / \mathrm{N}_{2}$ loadings at a specified $\mathrm{CO}_{2}$ composition.

Table 2. Performance Indicators for $P_{\mathrm{LOW}}=0.03 \mathrm{bar}, P_{\mathrm{INT}}=0.15 \mathrm{bar}$, and $T=298.15 \mathrm{~K}$

\begin{tabular}{lccccccc} 
& & \multicolumn{3}{c}{$\mathrm{En}\left[\mathrm{kWh} /\right.$ tonne $\mathrm{CO}_{2}$ cap. $]$} \\
\cline { 3 - 6 } adsorbent & $\mathrm{Pu}_{\mathrm{CO}_{2}}[\%]$ & $\mathrm{Re}_{\mathrm{CO}_{2}}[\%]$ & $\mathrm{BLO}$ & $\mathrm{EVAC}$ & total & $\mathrm{WC}_{\mathrm{CO}_{2}}\left[\mathrm{~mol} \mathrm{CO}_{2} / \mathrm{m}^{3}\right]$ \\
Mg-MOF-74 & 99.86 & 78.00 & 2.44 & 96.06 & 98.49 & 1146.36 \\
zeolite 13X & 99.96 & 79.30 & 1.65 & 92.49 & 94.13 & 1143.0 \\
UTSA-16 & 99.97 & 79.97 & 1.66 & 86.84 & 88.50 & 1674.4 \\
CS-AC & 94.42 & 55.63 & 19.19 & 99.49 & 118.68 & 297.2 \\
\hline
\end{tabular}

recovery. Table 2 provides the summary of the simulated results for the fixed operating condition. UTSA-16 gives $\mathrm{Pu}_{\mathrm{CO}_{2}}>99.9 \%$ and $\mathrm{Re}_{\mathrm{CO}_{2}} \approx 80 \%$ with the lowest energy consumption of 88.50 $\mathrm{kWh}_{\mathrm{e}} /$ tonne $\mathrm{CO}_{2}$ cap. when compared to the other adsorbents. Mg-MOF-74, zeolite 13X, and UTSA-16 give similar $\mathrm{CO}_{2}$ purity and recovery values for the given $P_{\mathrm{LOW}}$ and $P_{\mathrm{INT}}$, but there is a significant difference in energy values. CS-AC shows the worst performance among the four adsorbents considered.

As observed from Figure 3, the transitions for the various steps of the four-step VSA cycle with LPP indicate that for materials with high selectivity, a simple approach can be used to estimate the process performance. The blowdown and evacuation transitions start from state $\alpha$ and move horizontally, i.e., at constant $q_{\mathrm{CO}}^{*}$, until $y_{\mathrm{CO}_{2}}=1.00$ is reached and follow the $y_{\mathrm{CO}_{2}}=$ 1.00 isotherm until state $\gamma$ is reached. For the LPP step, the value of $y_{\mathrm{CO}_{2}}^{\delta}$ can be calculated by solving the isotherm expression by enforcing the condition $q_{\mathrm{CO}_{2}}^{* \gamma}=q_{\mathrm{CO}_{2}}^{* \delta}$. With all the four states now identified, the purity, recovery, energy consumption, and working capacity can be estimated. This approach is similar to those that have been used in the literature. ${ }^{31}$

3.2. Comparison of BAAM with the Detailed Model. In this section, the results from the BAAM are compared with the results obtained from the detailed model for the case of zeolite 13X. For a process design of the four-step VSA cycle with LPP using the detailed model, two pressures $\left(P_{\mathrm{LOW}}, P_{\mathrm{INT}}\right)$, feed velocity $\left(v_{\text {feed }}\right)$, and step times $\left(t_{\mathrm{BLO}}, t_{\mathrm{EVAC}}\right.$, and $\left.t_{\mathrm{ADS}}\right)$ are the typical design variables. In order to compare the product purity and recovery, it is important to understand the impact of these six variables on the process performance. Of the six variables, $P_{\text {LOW }}, P_{\text {INT }}, v_{\text {feed }}$ and $t_{\mathrm{ADS}}$ are the most critical ones. In a VSA process, the outlet flows typically drop exponentially as the pressure drops. In this case, if $t_{\mathrm{BLO}}$ and $t_{\mathrm{EVAC}}$ are kept sufficiently long, this will ensure that the purity and recovery from the process can be treated as the ideal case. In this study, $P_{\text {LOW }}$ and $P_{\text {INT }}$ are fixed at 0.03 and 0.15 bar respectively (as done in the 

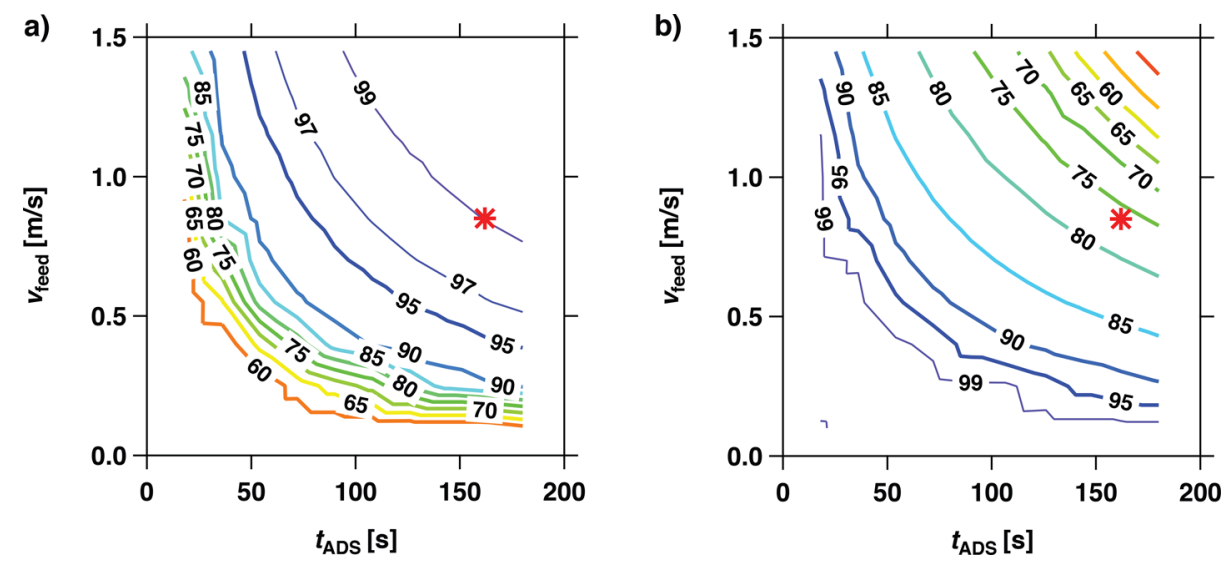

Figure 4. Contours of (a) $\mathrm{CO}_{2}$ purity and (b) $\mathrm{CO}_{2}$ recovery plotted as a function of $t_{\mathrm{ADS}}$ and $v_{\text {feed }}$ from the detailed model for the case of zeolite $13 \mathrm{X}$. $P_{\mathrm{H}}$ $=1 \mathrm{bar}, P_{\mathrm{INT}}=0.15 \mathrm{bar}, P_{\mathrm{LOW}}=0.03 \mathrm{bar}, t_{\mathrm{BLO}}=t_{\mathrm{EVAC}}=200 \mathrm{~s}$. The point shown as a red $*$ gives $P u_{\mathrm{CO}_{2}}$ and $R e_{\mathrm{CO}_{2}}$ comparable to the values obtained from the BAAM at $P_{\mathrm{H}}=1$ bar, $P_{\mathrm{INT}}=0.15$ bar.
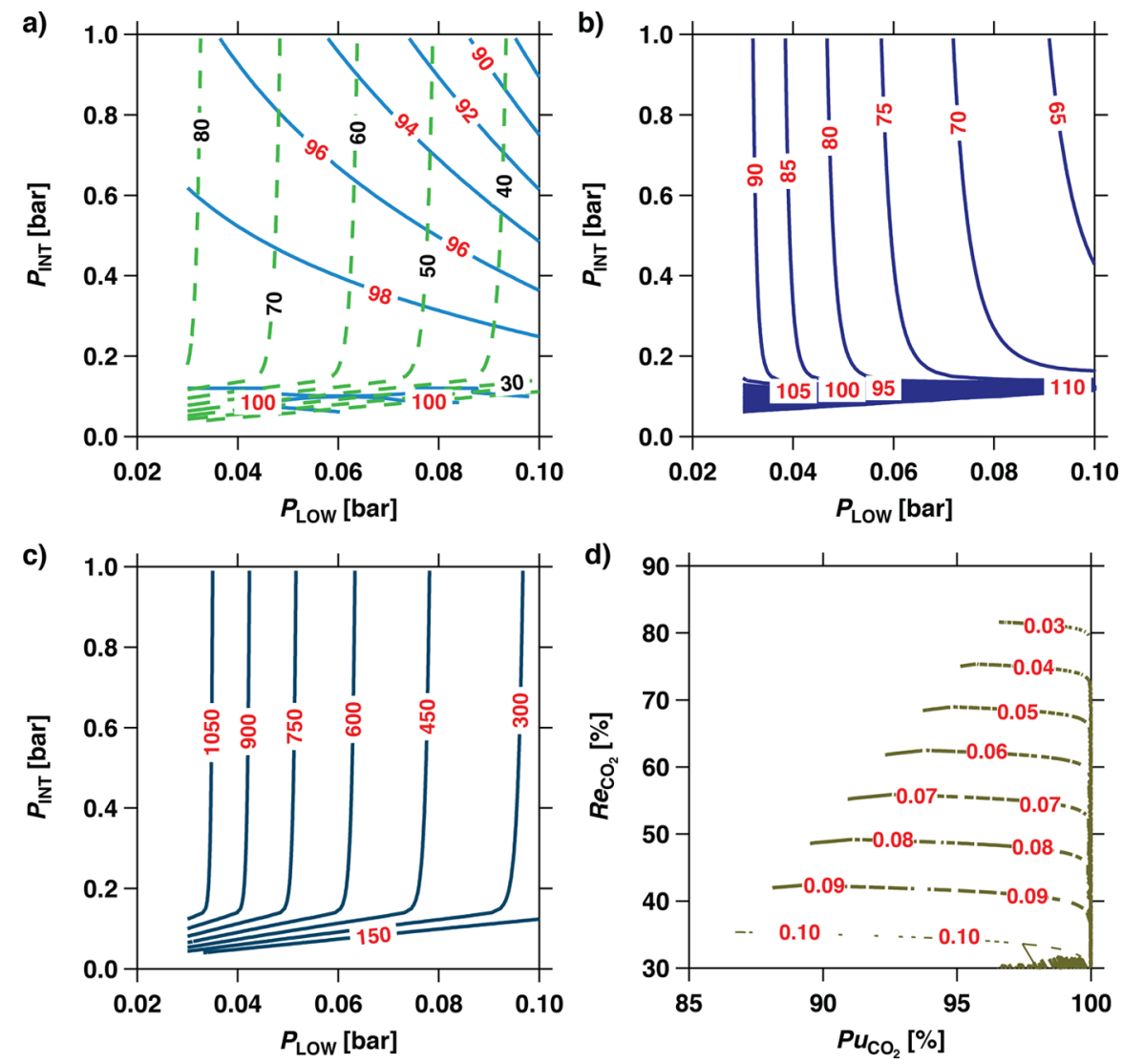

Figure 5. Contour plots of process indicators for zeolite $13 \mathrm{X}$ calculated from the $\mathrm{BAAM}$ (a) $\mathrm{Pu}_{\mathrm{CO}_{2}}$ (solid lines), and $\operatorname{Re}_{\mathrm{CO}_{2}}$ (dashed lines); (b) energy consumption in $\mathrm{kWh}_{\mathrm{e}} /$ tonne $\mathrm{CO}_{2}$ cap. (c) Working capacity in $\mathrm{mol} \mathrm{CO} 2 / \mathrm{m}^{3}$. Subfigure (d) shows the purity-recovery Pareto curves for various values of $P_{\text {LOW }}$.

previous section), while $t_{\mathrm{EVAC}}$ and $t_{\mathrm{BLO}}$ are set to $200 \mathrm{~s}$. Hence, we are left with $t_{\mathrm{ADS}}$ and $v_{\text {feed }}$ as the two design variables. A parametric study is then performed, using the detailed model, by varying $t_{\mathrm{ADS}}$ and $v_{\text {feed }}$ in the ranges $0<t_{\mathrm{ADS}}[\mathrm{s}]<180$, and $0<v_{\text {feed }}$ $[\mathrm{m} / \mathrm{s}]<1.5$, and the corresponding $\mathrm{CO}_{2}$ purity and recovery contours are plotted as a function of $t_{\mathrm{ADS}}$ and $v_{\text {feed }}$ in Figure 4. The detailed model simulation parameters used in this study are provided in the Supporting Information.

It is observed from Figure $4 \mathrm{a}$ that the $\mathrm{CO}_{2}$ purity increases and approaches close to $100 \%$ when $t_{\mathrm{ADS}}$ and $v_{\text {feed }}$ are high. Under these situations, the $\mathrm{CO}_{2}$ composition front has the opportunity to completely saturate the bed with the feed, and most of the $\mathrm{N}_{2}$ is removed in the blowdown step. This condition also means that large quantities of $\mathrm{CO}_{2}$ will be also lost as raffinate product in the adsorption step leading to poor recoveries as seen in the top right corner in Figure $4 \mathrm{~b}$. The design space is then scanned to pick an operating condition from the detailed model which closely corresponds to the $\mathrm{CO}_{2}$ purity and recovery values predicted from the BAAM. This is shown in red “*” in Figure 4. For this case, the energy consumption from the full model is 
found to be $125.68 \mathrm{kWh}_{\mathrm{e}}$ /tonne $\mathrm{CO}_{2}$ cap. which is significantly high when compared to the result from the BAAM for zeolite $13 \mathrm{X}$ given in Table 2, which is $94.13 \mathrm{kWh}_{\mathrm{e}} /$ tonne $\mathrm{CO}_{2}$ cap. To understand the differences in energy values, the same exercise was repeated, but now by assuming an isothermal operation and no pressure drop across the column. This required some changes to the operating conditions in order to ensure that the $\mathrm{CO}_{2}$ purity and recovery are comparable to the BAAM. The energy consumption from the detailed model dropped to $108 \mathrm{kWh}_{\mathrm{e}} /$ tonne $\mathrm{CO}_{2}$ cap. (15\% less than the previous case) for the similar values of $\mathrm{CO}_{2}$ purity and recovery. Assuming zero mass transfer resistance and axial dispersion would further reduce the energy consumption calculated from the detailed model. Summarizing, the BAAM can represent the dynamics of the detailed model only under certain fixed operating conditions, i.e., when the column is fully saturated with the feed and when the key assumptions of the BAAM are enforced on the detailed model. This is a key limitation of the BAAM.

\section{PARAMETRIC STUDY USING BAAM}

The previous section described the simulated results for a fixed $P_{\text {LOW }}$ and $P_{\text {INT }}$. Evaluation of the adsorbents for a fixed operating condition does not guarantee the correct ranking as the optimal performance of an adsorbent might be different from the fixed operating conditions that have been considered. A parametric study is performed for the case of zeolite $13 \mathrm{X}$ by varying $P_{\mathrm{LOW}}$ and $P_{\mathrm{INT}}$ in the ranges of $0.03 \leq P_{\mathrm{LOW}}[\mathrm{bar}] \leq 0.1$ and $P_{\mathrm{LOW}}+$ $0.01 \leq P_{\text {INT }}[$ bar $] \leq P_{\mathrm{H}}-0.01$ using the BAAM model. The contour plots of each of the performance indicators are generated to study the operating regions giving high product purity and recovery with lower energy consumption and higher working capacity.

Figure 5a shows that $\mathrm{CO}_{2}$ purity is dependent on the value of both $P_{\text {INT }}$ and $P_{\text {LOW. }}$. At a given $P_{\text {INT }}, \mathrm{CO}_{2}$ purity increases with decreasing $P_{\text {LOW. }}$. At a fixed $P_{\text {LOW }}, \mathrm{CO}_{2}$ purity increases with decreasing $P_{\mathrm{INT}}$. In the former case, reducing $P_{\mathrm{LOW}}$ increases the working capacity of the sorbent as the nonlinear portion of the isotherm is accessed. In the latter case, lowering $P_{\text {INT }}$ increases the amount of $\mathrm{N}_{2}$ that is removed thereby resulting in higher $\mathrm{CO}_{2}$ purity. A value of $\mathrm{Pu}_{\mathrm{CO}_{2}} \approx 100 \%$ is achieved when $P_{\mathrm{INT}}$ is close to its lower bound for a fixed $P_{\text {INT }}$. The $\mathrm{CO}_{2}$ recovery shows a similar trend for a fixed $P_{\mathrm{INT}}$. However, for a fixed $P_{\mathrm{LOW}}$, $P_{\text {INT }}$ has a minimal effect on recovery for $P_{\text {INT }}>0.15$ bar. From Figure 5a, it can be seen that the amount of $\mathrm{CO}_{2}$ removed is hardly affected in the range $0.15<P_{\text {INT }}[$ bar $]<1$, and this explains why $\mathrm{Re}_{\mathrm{CO}_{2}}$ is unaffected.

The energy contours are shown in Figure $5 b$. For a specific value of $P_{\mathrm{H}}$ and $y_{\mathrm{CO}_{2}}^{\mathrm{feed}}$, the total power consumption $\left[\mathrm{kWh}_{\mathrm{e}}\right]$ is only a function of $P_{\text {LOW. }}$. However, the specific power consumption $\left[\mathrm{kWh}_{\mathrm{e}} /\right.$ tonne $\mathrm{CO}_{2}$ cap.] depends on the amount of $\mathrm{CO}_{2}$ recovered in the evacuation step, in other words a function of the recovery. Hence, it comes as no surprise that the contours of the specific energy resemble that of the recovery; i.e., the specific power consumption is sensitive to $P_{\text {LOW }}$ for a fixed $P_{\text {INT }}$, but insensitive to $P_{\text {INT }}$ for $P_{\text {INT }}>0.15$ bar where $P_{\text {LOW }}$ is fixed.

The working capacity contours in Figure $5 c$ depict the same trend as seen with the recovery contours. Working capacities as high as $1050 \mathrm{~mol} \mathrm{CO} 2 / \mathrm{m}^{3}$ are achieved at very low pressures. The values of purity and recovery for a fixed value of $P_{\text {LOW }}$ and variable $P_{\text {INT }}$ are shown in Figure 5d. It is observed that the best combination of product purity and recovery is achieved when
$P_{\text {LOW }}$ is at the lowest value. The outermost front in Figure 5d, corresponding to $P_{\mathrm{LOW}}=0.03$, will be referred to as the purity-recovery "Pareto curve" for the BAAM model.

4.1. Comparison of BAAM with the Optimized Results from Detailed Model. In order to evaluate various adsorbents, it is important to compare their optimal performance. Figure 6a,b shows the purity-recovery Pareto curves for the four
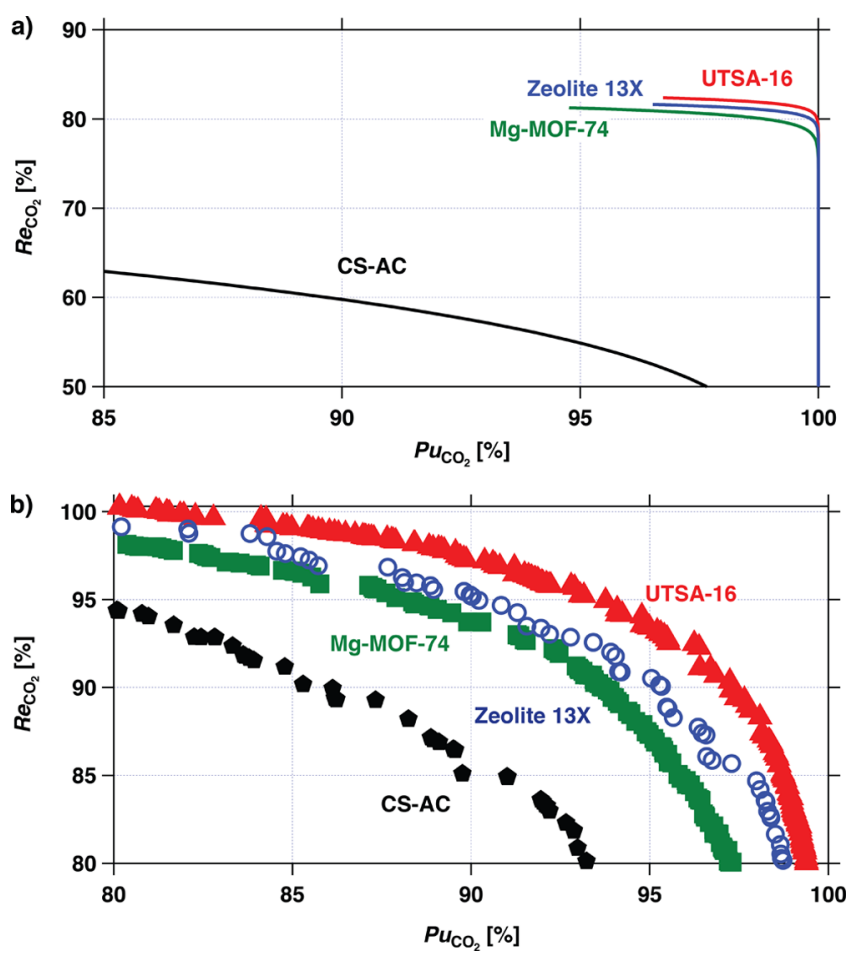

Figure 6. Comparison of $\mathrm{Pu}_{\mathrm{CO}_{2}}$ and $\mathrm{Re}_{\mathrm{CO}_{2}}$ Pareto curves obtained from (a) the BAAM (b) optimization using the detailed model. ${ }^{19}$ Figure $6 \mathrm{~b}$ reproduced with permission from Rajagopalan et al. ${ }^{19}$. Copyright 2016 Elsevier.

adsorbents obtained from the BAAM and the optimization of the detailed model, respectively. It is important to note that the values of $P_{\mathrm{H}}, P_{\text {LOW, }} y^{\text {feed }}$, and $T^{\text {feed }}$ are identical for both the detailed model and the BAAM. The detailed model considers $t_{\mathrm{ADS}}, v_{\mathrm{ADS}}, t_{\mathrm{BLO}}$, and $t_{\mathrm{EVAC}}$ as decision variables. Comparing Figure 6a,b, two observations become evident: (1) the maximum recovery values predicted from the BAAM are lower when compared to their detailed model counterparts; (2) the BAAM predicts a purity of $100 \%$ at relatively higher recovery for Mg-MOF-74, zeolite 13X, and UTSA-16. The former observation can be explained by the assumption in the BAAM that requires the column to be completely saturated with the feed in the adsorption step and partly due to the absence of axial concentration and temperature profiles in a perfectly mixed batch system. As a result, a significant amount of $\mathrm{CO}_{2}$ is lost during the adsorption step, whereas in the detailed model by controlling the position of $\mathrm{CO}_{2}$ front in the column, it is possible to prevent the loss of $\mathrm{CO}_{2}$ in the adsorption step. The latter observation can be understood by looking at the simplified process transitions in Figure 3 and also contour plots in Figure 5. When $P_{\text {INT }}$ is decreased from 1 to 0.15 bar, the recovery is fairly constant due to the flat blowdown profile for the case of zeolite $13 \mathrm{X}$, but the purity increases significantly until $P_{\mathrm{INT}}$ correspond- 
ing to $y_{\mathrm{CO}_{2}}=1.00$ is reached. At this point, the $\mathrm{CO}_{2}$ purity equals $100 \%$, but the recovery decreases when $P_{\mathrm{INT}}$ approaches $P_{\mathrm{LOW}}$.

A closer examination of Figure $6 \mathrm{a}, \mathrm{b}$ reveals an interesting correlation. Although the absolute values of $\mathrm{CO}_{2}$ purity and recovery do not match, the BAAM gives a correct ranking of adsorbents as compared with the detailed optimized ranking. Thus, based on maximization of purity-recovery values, the decreasing order of ranking of the adsorbent is UTSA-16 > zeolite 13X > Mg-MOF-74 > CS-AC.

\section{USING THE BAAM FOR ADSORBENT SCREENING}

In the previous section, the performance of the BAAM was compared with the detailed model under optimized conditions, and it was observed that the model underpredicts the purity and recovery performance although providing the correct ranking of the adsorbents. While this is helpful, the practical questions that need to be answered are, will a particular adsorbent be able to produce $\mathrm{Pu}_{\mathrm{CO}_{2}} \geq 95 \%$ and $\mathrm{Re}_{\mathrm{CO}_{2}} \geq 90 \%$ in order to satisfy USDepartment of Energy (US-DOE) requirements, and if so, what is the energy consumption of the process while guaranteeing USDOE targets? The aim of this section is to develop a classification and energy scaling approach that will help answer these questions.

Khurana and Farooq examined a set of adsorbents for adsorbent screening using the detailed model process optimization. $^{20}$ A total of 75 adsorbents, including a wide range of zeolites, zeolitic imidazolate frameworks (ZIFs), cation exchanged zeolites (CEZs), porous polymer networks (PPNs), and MOFs containing both real and hypothetical adsorbents were examined. A detailed multiobjective optimization aimed to maximize $P u_{\mathrm{CO}_{2}}$ and $R e_{\mathrm{CO}_{2}}$ was performed, and those adsorbents that met US-DOE requirements were screened. For those adsorbents that met these requirements, a separate optimization run that aimed to minimize energy while satisfying the $P u_{\mathrm{CO}_{2}}$ and $\mathrm{Re}_{\mathrm{CO}_{2}}$ constraints was performed. The results of this study are provided in the Supporting Information. This group of adsorbents along with the four that have been considered in the previous sections, totalling 79, were used to develop a classification and energy scaling approach for the BAAM. The adsorbents were described by the authors using a DSL model, and the fitting parameters are provided in the Supporting Information.

5.1. Purity - Recovery Classifier. The BAAM was used to generate the purity-recovery Pareto curves for the 79 adsorbents for a low pressure $P_{\text {LOW }}$ of 0.03 bar and different intermediate pressures. The purity-recovery Pareto curves obtained from the BAAM are plotted in Figure 7. Two colors are used to plot these curves: green curves are used to represent those adsorbents that were identified by Khurana and Farooq to have met the US-DOE purity-recovery constraints, and red curves were used to represent adsorbents that failed to meet the constraint. It is interesting to note that there is a clear clustering of green curves toward the top-right and the red ones toward the bottom left. This shows the potential of the BAAM to be used as a classifier. In order to reduce the two-dimensional measure (the Pareto curve), to a one-dimensional measure, the maximum Eucledian distance from the origin (denoted as $r_{\max }$ ) to the Pareto curve is considered as a proxy for the performance of an adsorbent. The mathematical description of $r_{\max }$ is given by

$$
r_{\max }=\operatorname{Max}\left(r\left(P u_{\mathrm{CO}_{2}}, \operatorname{Re}_{\mathrm{CO}_{2}}\right)\right)
$$

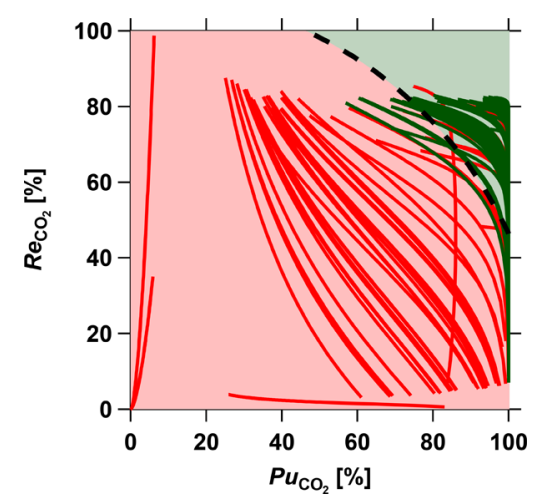

Figure 7. Collection of purity-recovery Pareto curves calculated using the BAAM for 79 adsorbents The green curves correspond to the adsorbents that met $\mathrm{Pu}_{\mathrm{CO}_{2}}=95 \%$ and $\mathrm{Re}_{\mathrm{CO}_{2}}=90 \%$, and the red ones correspond to those that did not satisfy based on the detailed model optimization. ${ }^{20}$ The black dashed line represents the locus of $r_{95-90}$. In order to meet the $\mathrm{Pu}_{\mathrm{CO}_{2}}=95 \%$ and $\mathrm{Re}_{\mathrm{CO}_{2}}=90 \%$ requirement, a point on the Pareto curve of an adsorbent obtained from the BAAM should fall above this curve.

where $r$ is the distance of each point on the Pareto curve, which is defined as

$$
r=\sqrt{\left(P u_{\mathrm{CO}_{2}}\right)^{2}+\left(R e_{\mathrm{CO}_{2}}\right)^{2}}
$$

Now, the goal is to determine the value of $r_{95-90}$ that provides the best classification for identifying materials that can provide $\mathrm{Pu}_{\mathrm{CO}_{2}} \geq 95 \%$ and $\mathrm{Re}_{\mathrm{CO}_{2}} \geq 90 \%$. The classification learner app from Statistics and Machine Learning Toolbox ${ }^{36}$ available in MATLAB was used to perform the linear discriminant analysis with a 5-fold cross validation with $r_{\max }$ for 79 adsorbents as the input and the $\mathrm{Pu}_{\mathrm{CO}_{2}}-\mathrm{Re}_{\mathrm{CO}_{2}}$ constraints from the detailed model optimization as the response. The results of the detailed model were converted into a binary output. A value of " 1 " was assigned if the purity-recovery constraint was achieved, and a value of " 0 " otherwise. The analysis resulted in $r_{95-90}=110.25$ with an accuracy of $87.3 \%$. In other words, an adsorbent with an $r_{\max } \geq$ $r_{95-90}=110.25$, is expected to meet US-DOE requirements, while an adsorbent with a $r_{\max }<110.25$ is not expected to meet the targets. The black dashed line, in Figure 7, represents the points for which $r=r_{95-90}=110.25$. This curve divides the whole plot into two regions one where the $\mathrm{Pu}_{\mathrm{CO}_{2}} / \mathrm{Re}_{\mathrm{CO}_{2}}$ constraints are satisfied (green shade), and the other where it is not (red shade).

The efficacy of the BAAM to classify a material according to its potential to satisfy US-DOE purity-recovery targets is compared with a variety of performance metrics that are used in the literature. A list of performance metrics tested and their definitions is given in Table 3. The details of these metrics have been discussed in a previous work. ${ }^{19}$ For each of the 79 adsorbents, the set of performance metrics were calculated based on their isotherms. Each metric was used as an input in MATLAB classification learner toolbox in order to predict the digital output ( 1 if purity-recovery constraints are met, and 0 otherwise). The classification accuracy is reported as the Matthew correlation coefficient (MCC), ${ }^{37}$ which is defined as

$$
\begin{aligned}
& \mathrm{MCC} \\
& =\frac{\mathrm{TP} \cdot \mathrm{TN}-\mathrm{FP} \cdot \mathrm{FN}}{\sqrt{(\mathrm{TP}+\mathrm{FP})(\mathrm{TP}+\mathrm{FN})(\mathrm{TN}+\mathrm{FP})(\mathrm{TN}+\mathrm{FN})}}
\end{aligned}
$$


Table 3. US-DOE Purity-Recovery Classification Accuracies of Commonly Used Adsorbent Performance Metrics Based on the Seventy-Nine Adsorbents Considered in This Study ${ }^{a}$

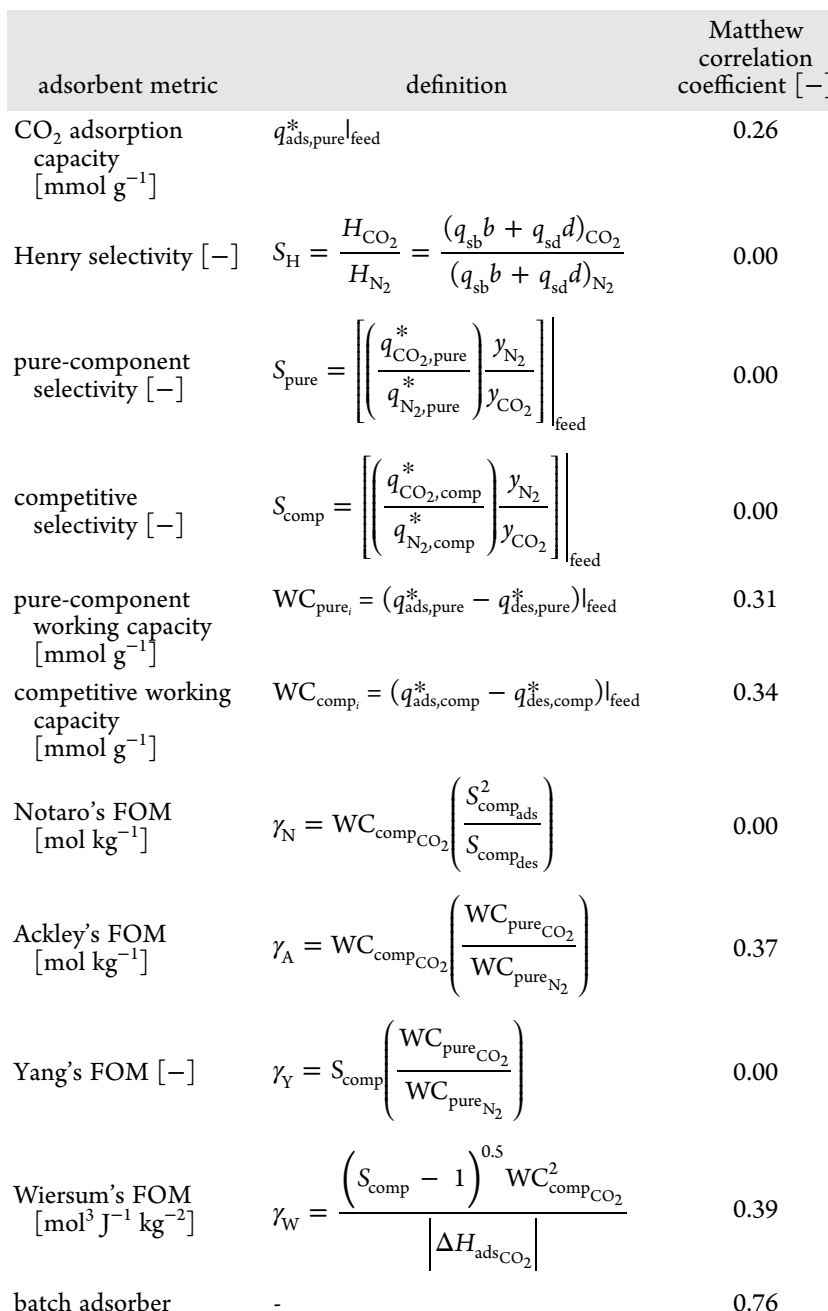

analogue model

${ }^{a}$ The equilibrium loadings at adsorption and desorption conditions are $q_{\text {ads }}^{*}=q^{*}\left(1 \mathrm{bar}, 298.15 \mathrm{~K}, y^{\mathrm{feed}}\right)$ and $q_{\text {des }}^{*}=q^{*}(0.03 \mathrm{bar}, 298.15 \mathrm{~K}$, $\left.y^{\text {feed }}\right)$, respectively. where the symbols TP, TN, FP, and FN refer to True-Positive, True-Negative, False-Positive, and False-Negative, respectively. These are obtained from the confusion matrix provided by the classification learner app. By definition the MCC can range from -1 to 1 . A value of -1 referring to the case where all population is misclassified; 0 referring to the case of a completely random metric; and 1 referring to the case where all population is correctly classified. The MCC for each of the adsorbent metric is listed in Table 3, and it can be observed that the BAAM with the MCC of 0.76 significantly outperforms every other metric. The next best performer is the Wiersum's figure of merit with an MCC value of 0.39 . This comparison highlights the advantage of the BAAM that has a high classification accuracy without any significant increase in the computational time.

5.2. Calculation of Minimum Energy. In order to compare the performances of different adsorbents, it is important that energy consumption has to be calculated at a specific $\mathrm{Pu}_{\mathrm{CO}_{2}}$ and $\mathrm{Re}_{\mathrm{CO}_{2}}$. The energy consumption, for the case of zeolite 13X, plotted in Figure $5 \mathrm{~b}$ is replotted in Figure 8a but now as a function of $\mathrm{Pu}_{\mathrm{CO}_{2}}$ and $\mathrm{Re}_{\mathrm{CO}_{2}}$. In addition to the contours of energy, the locus of $r_{95-90}$ is plotted as black dashed line. As it can be seen, the values of energy vary as one moves along the dashed line. The energy value decreases, reaches a minimum, and then increases. In this case, we choose the minimum energy that coincides with the locus of $r_{95-90}$ as being representative of the minimum energy for this adsorbent. This choice is not based on any physical argument, but is simply suggested as an approach that will allow the development of a consistent methodology.

The minimum energy values thus obtained from the BAAM for each of the adsorbents are compared with the corresponding minimum energy values from the detailed model in Figure 8b. It is important to note that only 35 of the 79 adsorbents that met the purity-recovery constraints were considered for the energy consumption calculations. A linear regression was performed to find the relationship between minimum energies calculated from the BAAM and that of the detailed model. This relationship is provided by

$$
E n_{\text {min, scaled }}=1.1446 E n_{\text {min, } \mathrm{BAAM}}+66.53
$$
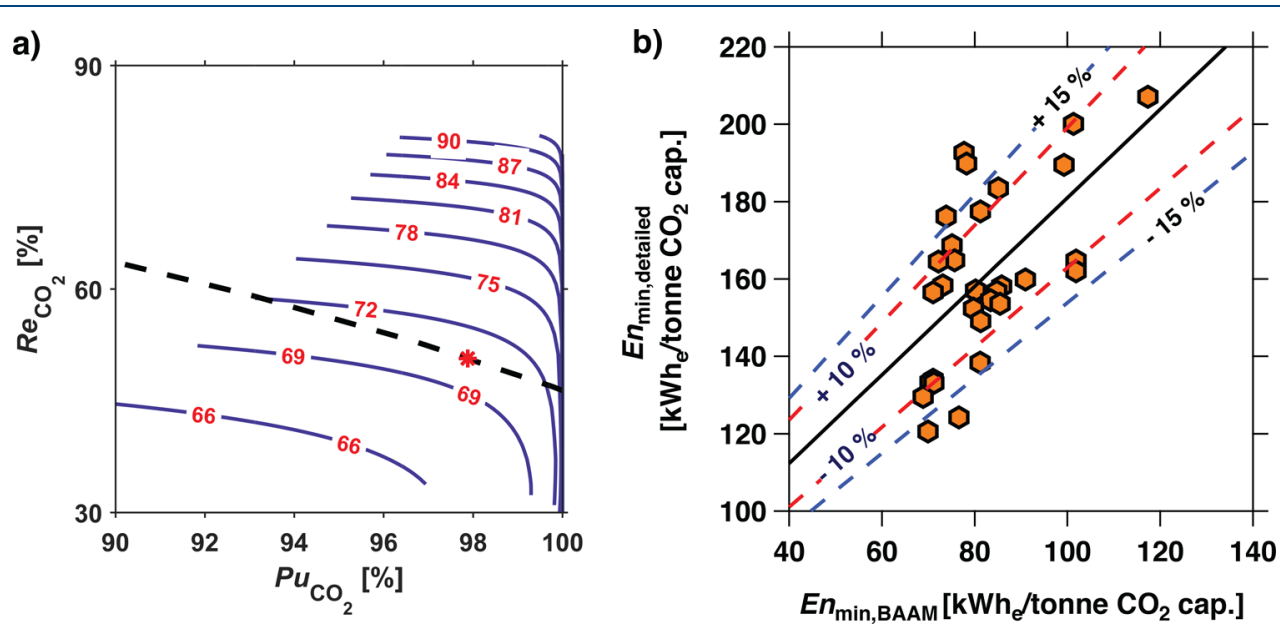

Figure 8. Calculation of energy consumption using the BAAM. (a) Energy contours as a function of $\mathrm{CO}_{2}$ purity and recovery for the case of zeolite 13X. The black dashed line represents the locus of $r_{95-90}$ with the minimum energy point being shown as a “*”. (b) Linear regression relating the minimum energy values computed from the BAAM to that of the optimization of the detailed model. 

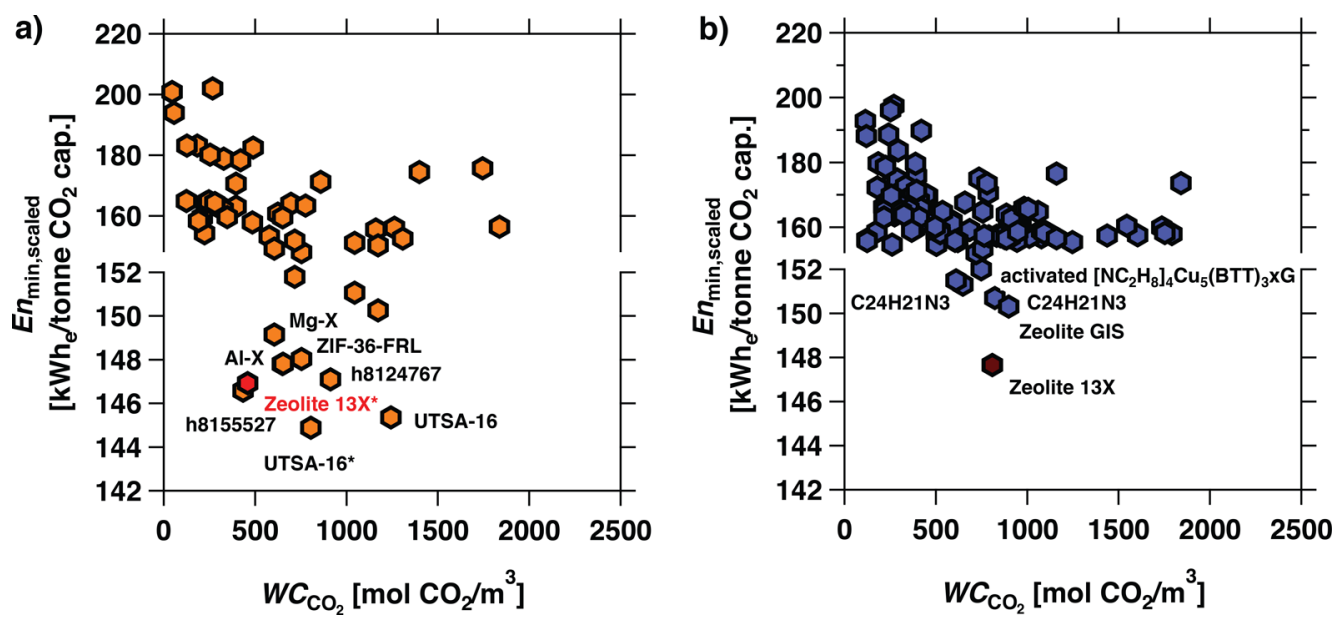

Figure 9. Plots of working capacity vs minimum energy calculated from the BAAM. (a) Shows the adsorbents considered by Khurana and Farooq ${ }^{20}$ and this work. (b) Shows the results from the screening of the NIST/ARPA-E database.

where $E n_{\text {min,scaled }}$ is the scaled energy that can be compared with results from a full model. As seen in Figure $8 \mathrm{~b}$, the minimum energies of $53 \%$ of the 35 adsorbents were predicted within $\pm 10 \%$, and that of $83 \%$ was predicted within $\pm 15 \%$ of the values from the detailed model. This accuracy seems reasonable considering the number of assumptions that went into developing the BAAM along with a significant reduction in computational time.

5.3. Ranking Metric. In order to compare the multiple adsorbents, both the minimum energy and working capacity need to be considered. The minimum energy and the corresponding working capacity for the 35 adsorbents that satisfied $\mathrm{Pu}_{\mathrm{CO}_{2}}-\mathrm{Re}_{\mathrm{CO}_{2}}$ constraints are shown in Figure 9a. An ideal adsorbent is the one with that has a low minimum energy consumption and corresponding high working capacity. This would form the bottom-right corner of the plot. It is worth noting here that zeolite $13 \mathrm{X}$, which is commercial and available at a modest cost, stands out as one of the materials with the lowest energy consumption. UTSA-16 that has a low $\mathrm{N}_{2}$ affinity, and a few hypothetical adsorbents, outperforms zeolite $13 \mathrm{X}$. These results are consistent with other reports in the literature. ${ }^{20}$ Some of the promising adsorbents are named in Figure 9a, while the values of the minimum energy calculated from the BAAM for the other adsorbents are provided in the Supporting Information.

\section{SCREENING OF THE NIST/ARPA-E DATABASE}

The National Institute of Standards and Technology (NIST) maintains a free and publicly accessible NIST/ARPA-E Database of Novel and Emerging Adsorbent Materials reported from a wide range of scientific literature. ${ }^{38}$ The database, which is growing at a rapid rate, includes data from published experimental and theoretical studies that are self-reported. In this section, the potential of the BAAM is demonstrated by using it to screen this large publicly available database. The objective is to identify those adsorbents that have the potential to meet USDOE purity-recovery targets and, if so, calculate their parasitic energies. The database consists of thousands of isotherm datafiles. Hence, it was important to develop a filtering scheme in order to identify those materials for which reliable adsorption isotherm data are available within the range of interest for postcombustion $\mathrm{CO}_{2}$ capture. The approach which is graphically described in the Supporting Information is briefly described here. A query was made through Python API script to retrieve all the adsorption isotherm data for all the adsorbent materials for which $\mathrm{CO}_{2}$ and $\mathrm{N}_{2}$ were reported as the adsorbates. The query resulted in 810 digital object identifiers (DOIs), which represents an unique information source. This process also yielded the isotherm data of other adsorbates and competitive isotherm data which were not of interest to the current work. Accordingly, these data points were removed in the first step before analyzing the data. This step identified those data points that contained isotherm information for pure $\mathrm{CO}_{2}$ and $\mathrm{N}_{2}$ on the material. This filter resulted in 757 DOIs and 1540 unique adsorbents. At this stage, it was important to convert the reported values of pressure, loading, and temperature into a common unit. Pressure and temperature units were reported only in bar and $\mathrm{K}$, respectively. These were retained as they are. However, equilibrium loadings were reported in a variety of units, and the corresponding conversion factors were applied to convert to a common unit (in this case " $\mathrm{mmol} / \mathrm{g}$ "). For loadings that were reported on a "per unit volume of the adsorbent", an adsorbent density of $1130 \mathrm{~kg} / \mathrm{m}^{3}$, that corresponding to zeolite $13 \mathrm{X}$, was chosen to convert to per unit weight of the adsorbent. Materials for which equilibrium loadings were reported on a "per unit-cell" basis were not considered further. This filter results in 743 DOIs and 1486 unique adsorbents. It is important to note here that multiple DOIs could report data on materials that have identical names. For example, data on "zeolite $13 X$ " was reported by 17 DOIs. In this study, each of these zeolites is considered as a unique adsorbent. The BAAM requires isotherm information for both $\mathrm{CO}_{2}$ and $\mathrm{N}_{2}$ at low pressures, i.e., < 1 bar and at $298 \mathrm{~K}$. Hence, it was important to identify data that included this information. Applying this filter, significantly reduced the search space to only 102 DOIs and 159 unique adsorbents. It was seen that most of the isotherm data for $\mathrm{CO}_{2}$ were reported at $273 \mathrm{~K}$, while $\mathrm{N}_{2}$ data were reported at $77 \mathrm{~K}$, primarily as a part of the adsorbent characterization experiments. Upon closer inspection of the data, it was found that some DOIs reported multiple $\mathrm{CO}_{2}$ isotherms for the same adsorbent at $298 \mathrm{~K}$. Investigating the primary reference revealed that these could be results of theoretical studies, experimental measurements, or even data from other research groups that were merely referenced to. Under these situations, each set of isotherm was assumed to belong to a variant of the same adsorbent. In a similar fashion, 
some DOIs reported multiple $\mathrm{N}_{2}$ isotherms. In such a situation, in order to avoid the multifarious combinations of $\mathrm{CO}_{2}$ and $\mathrm{N}_{2}$, we just considered the $\mathrm{N}_{2}$ isotherm that showed the highest loading at 1 bar pressure.

The $\mathrm{CO}_{2}$ and $\mathrm{N}_{2}$ isotherm data hence obtained was described by single site Langmuir (SSL) model by forcing equal saturation loadings for the two adsorbates, thereby ensuring thermodynamic consistency. Note that the SSL is a special form of the DSL in which only one of two Langmuirian terms is retained. The complete list of materials along with the SSL isotherm parameters is provided in the Supporting Information. The BAAM was then run to identify adsorbents that could meet the US-DOE $\mathrm{Pu}_{\mathrm{CO}_{2}}-\mathrm{Re}_{\mathrm{CO}_{2}}$ constraints. Of the 197 materials, a total of 120 were found to meet the requirements. The minimum energy and the corresponding working capacity for these 120 materials were computed and depicted in Figure $9 \mathrm{~b}$. The process of isotherm fitting and the BAAM calculations was completed in less than two seconds per adsorbent. Zeolite $13 \mathrm{X}$ still stands out as the best-performing adsorbent in terms of minimum energy consumption from screening the NIST database. A few other zeolites, microporous organic polymers (MOPs), and MOFs, namely, zeolite GIS, $\mathrm{C} 24 \mathrm{H} 21 \mathrm{~N} 3$, and activated $\left[\mathrm{NC}_{2} \mathrm{H}_{8}\right]_{4} \mathrm{Cu}_{5^{-}}$ $(\mathrm{BTT})_{3} \mathrm{xG}$ offer low parasitic energies. It is important to acknowledge that it is quite possible that promising adsorbents could have been missed based on the filtering approach that was adopted. This highlights the fact that reporting of equilibrium data for both $\mathrm{CO}_{2}$ at capture conditions and $\mathrm{N}_{2}$ is critical in order to perform reliable screening. ${ }^{39}$ However, the objective of this exercise, which was to showcase the flexibility and speed of the BAAM that can be adapted to any large database, has been sufficiently demonstrated.

\section{CONCLUSIONS}

In this work, a batch adsorber analogue model (BAAM) based on the framework described by Maring and Webley has been developed. It is based on several simplifying assumptions that aims to reduce the computational complexity. Specifically, the adsorber is considered as a mixed system that is isothermal and with the solid reaching instantaneous equilibrium with the fluid phase. This reduces the PDEs to ODEs and eliminates the heat balances and the solid-fluid mass balances. It was shown that the results of the BAAM can be represented on a isotherm plot that requires only the description of the competitive behavior of $\mathrm{CO}_{2}$ and $\mathrm{N}_{2}$. Under certain conditions, a simple graphical solution, which does not require the solution of ODEs, can be obtained. By comparing the results of the BAAM with those from detailed optimization studies, a classification model was developed that showed a Matthew correlation coefficient of 0.76 in determining whether an adsorbent can produce a $\mathrm{Pu}_{\mathrm{CO}_{2}} \geq$ $95 \%$ and $\mathrm{Re}_{\mathrm{CO}_{2}} \geq 90 \%$ when implemented in a full-scale process. A simple linear relationship to calculate the minimum energy calculated from the BAAM was developed. It was able to estimate the minimum energy within $\pm 15 \%$ for over $83 \%$ adsorbents. The ability of the model to screen large number of materials was demonstrated by considering 197 adsorbents from the NIST/ARPA-E database.

In this work the shortcomings and advantages of the BAAM were studied by comparing its result with those from detailed models. The BAAM has four important shortcomings. First, the model is based on several assumptions that are far from reality. Real VSA units work under non-isothermal conditions; mass and heat transfer rates are finite, and there is a pressure drop across the column. In fact, as discussed, the ability to control the position of the mass and thermal fronts is the basis of an adsorption process. Second, it has a finite accuracy in being able to either determine purity-recovery classification or to calculate the energy calculation. Hence, it is advisable not to select adsorbents purely on the basis of the BAAM or any other simplified model as suggested in many papers in the literature. Third, the operating conditions obtained from the BAAM cannot be translated to an experimental demonstration. Fourth, while the BAAM provides a reasonable estimate of the energy consumption, owing to the imposition of the equilibrium assumption, it cannot provide any information about the productivity. Costing studies have shown that both the parasitic energy and productivity play comparable roles in deciding the cost of $\mathrm{CO}_{2}$ capture. Hence, detailed modeling and costing analysis are required to select adsorbents for scale-up. ${ }^{40}$ The key advantages of the BAAM are 2-fold. First, the model captures the underlying physics that governs the separation and provides a graphical method to rationalize the results. Second, is the speed with which the purity-recovery classification and minimum energy consumption can be calculated. It takes less than a second to perform these calculations on a standard laptop computer, compared to a few days that is required for detailed process optimization. It was shown that in terms of the accuracy with which the classification can be performed, the BAAM outperforms simple adsorption metrics without any increase in computational time. In conclusion, it is recommended that the BAAM be used to perform a preliminary screening and identify a handful of adsorbents that can be further studied using the detailed model combined with rigorous optimization. This approach could potentially increase the success rates in screening materials while reducing the time for screening. Further, the ability to predict broad trends and to understand them based just on the isotherms still makes this a powerful tool in the suite of models that are available to process engineers.

\section{ASSOCIATED CONTENT}

\section{S Supporting Information}

The Supporting Information is available free of charge on the ACS Publications website at DOI: 10.1021/acs.iecr.8b05420.

Batch adsorbent analogue model transitions for $\mathrm{Mg}$ MOF-74 and UTSA-16; table of dual-site Langmuir adsorption isotherm parameters considered by Khurana and Farooq; table containing the summary of purityrecovery classification and calculation of minimum energy from BAAM; flowchart for filtering adsorbents from NIST/ARPA-E database; single site Langmuir adsorption isotherm parameters and performance indicators for adsorbents from the NIST/ARPA-E database; table containing the model equations and boundary conditions for the detailed model (PDF)

\section{AUTHOR INFORMATION}

\section{Corresponding Author}

*E-mail: arvind.rajendran@ualberta.ca.

\section{ORCID}

Ashwin Kumar Rajagopalan: 0000-0001-8306-455X

Adolfo M. Avila: 0000-0001-5304-008X

Arvind Rajendran: 0000-0003-4367-4892 


\section{Present Address}

\#(A.K.R.) Institute of Process Engineering, ETH Zurich, $\mathrm{CH}$ 8092 Zurich, Switzerland.

\section{Notes}

The authors declare no competing financial interest.

Source code: Upon publication of the paper, a free copy of the MATLAB code can be accessed at https://github.com/ ArvindRajendran/BAAM.

\section{ACKNOWLEDGMENTS}

Funding from the National Science and Engineering Research Council (NSERC) of Canada through Discovery Grant RGPIN2014-06164, NSERC CREATE program in $\mathrm{CO}_{2}$ capture, and Canada First Research Excellence Fund through the University of Alberta Future Energy systems are acknowledged. Discussions with Vinay Prasad, University of Alberta, are appreciated.

\section{NOMENCLATURE}

\section{Roman Symbols}

$b$ adsorption equilibrium constant for high energy site $\left[\mathrm{m}^{3}\right.$ $\mathrm{mol}^{-1}$ ]

C fluid phase concentration $\left[\mathrm{mol} \mathrm{m}^{-3}\right]$

$d$ adsorption equilibrium constant for low energy site $\left[\mathrm{m}^{3}\right.$ $\mathrm{mol}^{-1}$ ]

En energy consumption [ $\mathrm{kWh}_{\mathrm{e}}$ tonne of $\mathrm{CO}_{2}$ cap. $^{-1}$ ]

$F$ adsorbent figure of merit $\left[\mathrm{mol} \mathrm{kg} \mathrm{kg} \mathrm{mol}^{3} \mathrm{~J}^{-1} \mathrm{~kg}^{-2}\right.$ or - $]$

$k \quad$ adiabatic constant [-]

$M \quad$ molecular weight $\left[\mathrm{g} \mathrm{mol}^{-1}\right]$

$N$ number of moles [mol]

$P \quad$ total pressure [bar]

$\mathrm{Pu}$ purity [\%]

$q^{*} \quad$ equilibrium solid phase loading $\left[\mathrm{mol} \mathrm{kg}^{-1}\right]$

$Q \quad$ outlet molar flow rate $\left[\mathrm{mol} \mathrm{s}^{-1}\right]$

$r \quad$ Euclidian distance of a purity-recovery point on the Pareto front from the origin

$R_{\mathrm{g}} \quad$ Universal gas constant $\left[\mathrm{Pa} \mathrm{m} \mathrm{mol}^{-1} \mathrm{~K}^{-1}\right]$

Re recovery [\%]

$S$ selectivity

$t$ time $[\mathrm{s}]$

$T$ temperature $[\mathrm{K}]$

$\Delta U$ internal energy $\left[\mathrm{J} \mathrm{mol}^{-1}\right]$

$v \quad$ velocity $\left[\mathrm{m} \mathrm{s}^{-1}\right]$

$V \quad$ column volume $\left[\mathrm{m}^{3}\right]$

$W \quad$ vacuum pump work done $[\mathrm{J}]$

$W C$ working capacity $\left[\mathrm{mol} \mathrm{m}{ }^{-3}\right.$ or $\left.\mathrm{mol} \mathrm{kg}^{-1}\right]$

$w$ adsorbent mass $[\mathrm{kg}]$

$y$ mole fraction $[-]$

\section{Greek Symbols}

$\alpha$ state at the end of adsorption step [-]

$\beta$ state at the end of blowdown step [-]

$\gamma$ state at the end of light product pressurization step $[-]$

$\delta$ state at the end of evacuation step [-]

$\epsilon$ bed voidage [-]

$\eta$ vacuum pump efficiency [\%]

$\rho$ particle density $\left[\mathrm{kg} \mathrm{m}^{-3}\right]$

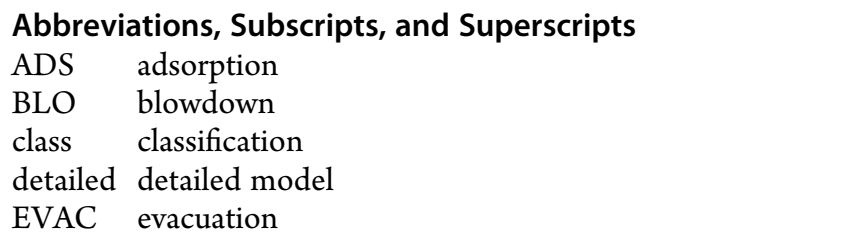

$\begin{array}{ll}\text { fluid } & \text { fluid phase } \\ \text { H } & \text { high } \\ \text { i } & \text { index of species } \\ \text { INT } & \text { intermediate } \\ \text { LPP } & \text { light product pressurization } \\ \text { max } & \text { maximum } \\ \text { min } & \text { minimum } \\ \text { scaled } & \text { linear regression fit energy } \\ \text { solid } & \text { solid phase } \\ \text { total } & \text { fluid phase }+ \text { solid phase }\end{array}$

\section{Acronyms}

BAAM batch adsorber analogue model

CCS carbon capture and storage

CEZ cation exchanged zeolites

CSS cyclic steady state

DOI digital object identifier

FVM finite volume method

GA genetic algorithm

MOF metal-organic framework

MCC Matthews correlation coefficient

MW Maring and Webley's simplified model

ODE ordinary differential equation

PDE partial differential equation

PPN porous polymer network

PSA pressure swing adsorption

VSA vacuum swing adsorption

TSA temperature swing adsorption

ZIF zeolitic imidazolate frameworks

\section{REFERENCES}

(1) Metz, B.; Davidson, O.; De Coninck, H.; Loos, M.; Meyer, L. IPCC, IPCC special report on carbon dioxide capture and storage. Prepared by Working Group III of the Intergovernmental Panel on Climate Change. Cambridge, United Kingdom and New York, NY, USA 2005, 442 .

(2) Smit, B.; Reimer, J. A.; Oldenburg, C. M.; Bourg, I. C. Introduction to Carbon Capture and Sequestration; World Scientific, 2014.

(3) Bui, M.; Adjiman, C. S.; Bardow, A.; Anthony, E. J.; Boston, A.; Brown, S.; Fennell, P. S.; Fuss, S.; Galindo, A.; Hackett, L. A.; Hallett, J. P.; Herzog, H. J.; Jackson, G.; Kemper, J.; Krevor, S.; Maitland, G. C.; Matuszewski, M.; Metcalfe, I. S.; Petit, C.; Puxty, G.; Reimer, J.; Reiner, D. M.; Rubin, E. S.; Scott, S. A.; Shah, N.; Smit, B.; Trusler, J. P. M.; Webley, P.; Wilcox, J.; Mac Dowell, N. Carbon capture and storage (CCS): the way forward. Energy Environ. Sci. 2018, 11, 1062-1176.

(4) Wilcox, J. Carbon Capture; Springer Science \& Business Media, 2012

(5) Haghpanah, R.; Majumder, A.; Nilam, R.; Rajendran, A.; Farooq, S.; Karimi, I. A.; Amanullah, M. Multiobjective optimization of a fourstep adsorption process for postcombustion $\mathrm{CO}_{2}$ capture via finite volume simulation. Ind. Eng. Chem. Res. 2013, 52, 4249-4265.

(6) Webley, P. A. Adsorption technology for $\mathrm{CO}_{2}$ separation and capture: a perspective. Adsorption 2014, 20, 225-231.

(7) Sircar, S. Pressure swing adsorption. Ind. Eng. Chem. Res. 2002, 41, $1389-1392$.

(8) Ruthven, D.; Farooq, S.; Knaebel, K. Pressure Swing Adsorption; Wiley, 1993

(9) D’Alessandro, D. M.; Smit, B.; Long, J. R. Carbon dioxide capture: prospects for new materials. Angew. Chem., Int. Ed. 2010, 49, 60586082.

(10) Samanta, A.; Zhao, A.; Shimizu, G. K.; Sarkar, P.; Gupta, R. Postcombustion $\mathrm{CO}_{2}$ capture using solid sorbents: a review. Ind. Eng. Chem. Res. 2012, 51, 1438-1463.

(11) James, S. L. Metal-organic frameworks. Chem. Soc. Rev. 2003, 32, 276-288. 
(12) Choi, S.; Drese, J. H.; Jones, C. W. Adsorbent materials for carbon dioxide capture from large anthropogenic point sources. ChemSusChem 2009, 2, 796-854.

(13) Harlick, P. J.; Tezel, F. H. An experimental adsorbent screening study for $\mathrm{CO}_{2}$ removal from $\mathrm{N}_{2}$. Microporous Mesoporous Mater. 2004, $76,71-79$.

(14) Yazaydin, A. O.; Snurr, R. Q.; Park, T.-H.; Koh, K.; Liu, J.; LeVan, M. D.; Benin, A. I.; Jakubczak, P.; Lanuza, M.; Galloway, D. B.; Low, J. J.; Willis, R. R. Screening of metal-organic frameworks for carbon dioxide capture from flue gas using a combined experimental and modeling approach. J. Am. Chem. Soc. 2009, 131, 18198-18199.

(15) Krishna, R.; van Baten, J. M. A comparison of the $\mathrm{CO}_{2}$ capture characteristics of zeolites and metal-organic frameworks. Sep. Purif. Technol. 2012, 87, 120-126.

(16) Krishna, R. Screening metal-organic frameworks for mixture separations in fixed-bed adsorbers using a combined selectivity/ capacity metric. RSC Adv. 2017, 7, 35724-35737.

(17) Lin, L.-C.; Berger, A. H.; Martin, R. L.; Kim, J.; Swisher, J. A.; Jariwala, K.; Rycroft, C. H.; Bhown, A. S.; Deem, M. W.; Haranczyk, M.; Smit, B. In silico screening of carbon-capture materials. Nat. Mater. 2012, 11, 633 .

(18) Berger, A. H.; Bhown, A. S. Optimizing solid sorbents for $\mathrm{CO}_{2}$ capture. Energy Procedia 2013, 37, 25-32.

(19) Rajagopalan, A. K.; Avila, A. M.; Rajendran, A. Do adsorbent screening metrics predict process performance? A process optimization based study for post-combustion capture of $\mathrm{CO}_{2}$. Int. J. Greenhouse Gas Control 2016, 46, 76-85.

(20) Khurana, M.; Farooq, S. Adsorbent screening for postcombustion $\mathrm{CO}_{2}$ capture: a method relating equilibrium isotherm characteristics to an optimum vacuum swing adsorption process performance. Ind. Eng. Chem. Res. 2016, 55, 2447-2460.

(21) Haghpanah, R.; Rajendran, A.; Farooq, S. $\mathrm{CO}_{2}$ capture from postcombustion flue gas on a carbon molecular sieve. American Institute of Chemical Engineers (AIChE), Annual Meeting, Minneapolis, USA, 2011

(22) Hasan, M. F.; First, E. L.; Floudas, C. A. Cost-effective $\mathrm{CO}_{2}$ capture based on in silico screening of zeolites and process optimization. Phys. Chem. Chem. Phys. 2013, 15, 17601-17618.

(23) Casas, N.; Schell, J.; Blom, R.; Mazzotti, M. MOF and UiO-67/ MCM-41 adsorbents for pre-combustion $\mathrm{CO}_{2}$ capture by PSA: Breakthrough experiments and process design. Sep. Purif. Technol. 2013, 112, 34-48.

(24) Leperi, K. T.; Snurr, R. Q.; You, F. Optimization of two-stage pressure/vacuum swing adsorption with variable dehydration level for postcombustion carbon capture. Ind. Eng. Chem. Res. 2016, 55, 33383350

(25) Nikolaidis, G. N.; Kikkinides, E. S.; Georgiadis, M. C. An integrated two-stage $\mathrm{P} / \mathrm{VSA}$ process for postcombustion $\mathrm{CO}_{2}$ capture using combinations of adsorbents Zeolite $13 \mathrm{X}$ and Mg-MOF-74. Ind. Eng. Chem. Res. 2017, 56, 974-988.

(26) Khurana, M.; Farooq, S. Integrated adsorbent-process optimization for carbon capture and concentration using vacuum swing adsorption cycles. AIChE J. 2017, 63, 2987-2995.

(27) Beck, J.; Friedrich, D.; Brandani, S.; Fraga, E. S. Multi-objective optimization using surrogate models for the design of VPSA systems. Comput. Chem. Eng. 2015, 82, 318-329.

(28) Hasan, M. F.; Karimi, I.; Farooq, S.; Rajendran, A.; Amanullah, M. Comput.-Aided Chem. Eng.; Elsevier, 2011; Vol. 29; pp 402-406.

(29) Walton, K. S.; Sholl, D. S. Research challenges in avoiding "showstoppers" in developing materials for large-scale energy applications. Joule 2017, 1, 208-211.

(30) Maring, B. J.; Webley, P. A. A new simplified pressure/vacuum swing adsorption model for rapid adsorbent screening for $\mathrm{CO}_{2}$ capture applications. Int. J. Greenhouse Gas Control 2013, 15, 16-31.

(31) Zhao, R.; Deng, S.; Wang, S.; Zhao, L.; Zhang, Y.; Liu, B.; Li, H.; $\mathrm{Yu}, \mathrm{Z}$. Thermodynamic research of adsorbent materials on energy efficiency of vacuum-pressure swing adsorption cycle for $\mathrm{CO}_{2}$ capture. Appl. Therm. Eng. 2018, 128, 818-829.
(32) Krishnamurthy, S.; Rao, V. R.; Guntuka, S.; Sharratt, P.; Haghpanah, R.; Rajendran, A.; Amanullah, M.; Karimi, I. A.; Farooq, S. $\mathrm{CO}_{2}$ capture from dry flue gas by vacuum swing adsorption: a pilot plant study. AIChE J. 2014, 60, 1830-1842.

(33) Haghpanah, R.; Nilam, R.; Rajendran, A.; Farooq, S.; Karimi, I. A. Cycle synthesis and optimization of a VSA process for postcombustion $\mathrm{CO}_{2}$ capture. AIChE J. 2013, 59, 4735-4748.

(34) Hosseinzadeh Hejazi, S. A.; Estupiñan Perez, L.; Pai, K. N.; Rajendran, A.; Kuznicki, S. M. Single-and Dual-stage High-purity Oxygen Production using Silver-Exchanged Titanosilicates (Ag-ETS10). Ind. Eng. Chem. Res. 2018.578997

(35) Krishnamurthy, S.; Haghpanah, R.; Rajendran, A.; Farooq, S. Simulation and optimization of a dual-adsorbent, two-bed vacuum swing adsorption process for $\mathrm{CO}_{2}$ capture from wet flue gas. Ind. Eng. Chem. Res. 2014, 53, 14462-14473.

(36) MATLAB 9.4 and Statistics and Machine Learning Toolbox 11.3; The MathWorks, Inc.: Natick, MA, 2018.

(37) Matthews, B. W. Comparison of the predicted and observed secondary structure of T4 phage lysozyme. Biochim. Biophys. Acta, Protein Struct. 1975, 405, 442-451.

(38) Siderius, D.; Shen, V.; Johnson, R., III; van Zee, R. NIST/ARPAE Database of Novel and Emerging Adsorbent Materials, NIST Standard Reference Database Number 205; National Institute of Standards and Technology: Gaithersburg, MD, 2017; http://adsorbents.nist.gov [retrieved August 17, 2018].

(39) Rajagopalan, A. K.; Rajendran, A. The effect of nitrogen adsorption on vacuum swing adsorption based post-combustion $\mathrm{CO}_{2}$ capture. Int. J. Greenhouse Gas Control 2018, 78, 437-447.

(40) Susarla, N.; Haghpanah, R.; Karimi, I.; Farooq, S.; Rajendran, A.; Tan, L. S. C.; Lim, J. S. T. Energy and cost estimates for capturing $\mathrm{CO}_{2}$ from a dry flue gas using pressure/vacuum swing adsorption. Chem. Eng. Res. Des. 2015, 102, 354-367. 